\title{
Predicting the onset of freezing of gait: A Longitudinal study
}

\author{
Kaylena A. Ehgoetz Martens ${ }^{1}$, PhD, Emily L. Lukasik ${ }^{1}$, MBMSc, Matthew J. Georgiades ${ }^{1}$, \\ BSc, Moran Gilat ${ }^{1}$, MSc, Julie M. Hall ${ }^{1,2}$, MSc, Courtney C. Walton ${ }^{1}$, PhD, Simon J.G. \\ Lewis ${ }^{1}, \mathrm{MD}, \mathrm{NHMRC}, \mathrm{PhD}$

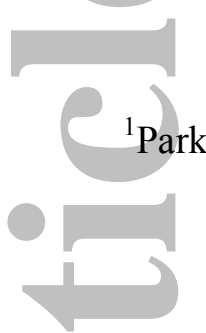 \\ Parkinson's Disease Research Clinic, Brain and Mind Centre, University of Sydney \\ ${ }^{2}$ School of Social Sciences and Psychology, Western Sydney University \\ Corresponding Author: \\ Kaylena A. Ehgoetz Martens \\ Parkinson's Disease Research Clinic, Brain and Mind Centre, University of Sydney \\ 100 Mallet Street, New South Wales, 2050 \\ Phone +610293510870 \\ kaylena.ehgoetzmartens@sydney.edu.au
}

Running Title: Anxiety is a predictor of FOG onset

Word count paper: 2968

Number of references: 30

Number of tables: 2

Number of figures: 3

Keywords: Parkinson's disease, freezing of gait, cognition, anxiety, motor, sleep

Author Disclosures: Kaylena A. Ehgoetz Martens - Reports no disclosures; Emily L. Lukasik

- Reports no disclosures; Matthew J. Georgiades - Reports no disclosures;Moran Gilat -

Reports no disclosures; Julie M. Hall - Reports no disclosures; Courtney C. Walton -

Reports no disclosures; Simon J.G. Lewis - Reports no disclosures

This work was supported by funding to Forefront, a collaborative research group dedicated to

the study of non-Alzheimer disease degenerative dementias, from the National Health and

Medical Research Council of Australia program grant (\#1037746 and \#1095127). Kaylena A.

Ehgoetz Martens is supported by a Parkinson Canada Postdoctoral fellowship. Matthew J.

Georgiades is supported by the Sydney Medical School RA Money Postgraduate Research

Scholarship in Neuroscience. Moran Gilat is supported by a University of Sydney

This is the author manuscript accepted for publication and has undergone full peer review but has not been through the copyediting, typesetting, pagination and proofreading process, which may lead to differences between this version and the Version record. Please cite this article as doi:10.1002/ mds.27208. 
International Scholarship. Julie M. Hall is supported by a Western Sydney University Postgraduate Research Award. These funding organizations did not play any role in the design and conductor of the study; collection, management, analysis or interpretation of the (a) data; nor the preparation, review, approval of the manuscript, or decision to submit the manuscript for publication.
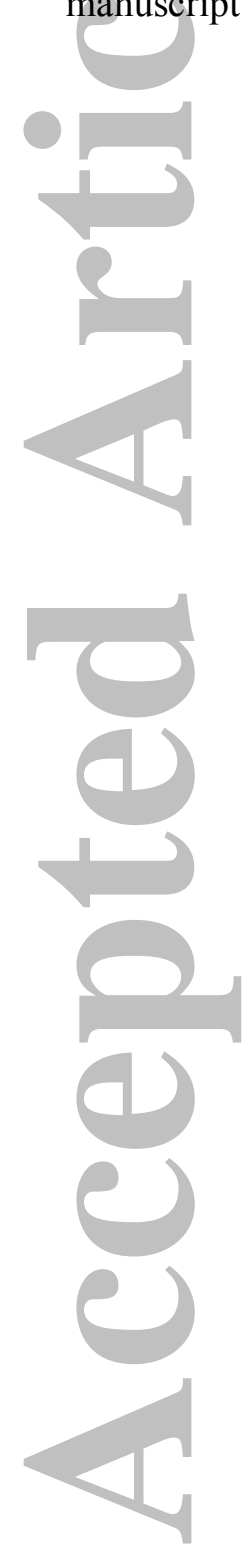


\begin{abstract}
Objective: Freezing of gait (FOG) is a disabling symptom of Parkinson's disease (PD) that ultimately affects approximately $80 \%$ of patients, yet very little research has focused on predicting the onset of FOG and tracking the longitudinal progression of symptoms prior to its onset. The objective of the current study was to examine longitudinal data spanning the transition period where patients with PD developed FOG to identify symptoms that may precede freezing and create a prediction model that identifies those 'at risk' for developing FOG in the year to follow.
\end{abstract}

Methods: Two-hundred and twenty-one patients with PD were divided into three groups (88 non-freezers, 41 transitional-freezers, and 92 continuing-freezers) based on their responses to the validated FOG-Questionnaire Item 3 at baseline and follow-up. Critical measures across motor, cognitive, mood and sleep domains were assessed at two time points approximately one year apart.

Results: A logistic regression model which included age, disease duration, gait symptoms, motor phenotype, attentional set-shifting, and mood measures could predict with $70 \%$ and $90 \%$ accuracy, respectively those patients who would and would not develop FOG over the next year. Notably, the FOG-Questionnaire total and the Anxiety section of the Hospital Anxiety and Depression Scale were the strongest predictors, and alone, could significantly predict if one might develop FOG in the next 15 months with $82 \%$ accuracy.

Conclusions: Our results suggest that it is possible to identify the majority of patients who will develop FOG in the following year potentially allowing targeted interventions to delay or possibly even prevent the onset of freezing. 


\section{INTRODUCTION}

Freezing of gait (FOG) is a common and complex symptom in Parkinson's disease (PD) with a poorly understood onset [1] and limited options for successful treatment [2]. Whilst approximately $80 \%$ of patients ultimately develop FOG [3], predicting who and when is currently not possible, thus thwarting targeted interventions.

To date, only two studies have followed early stage PD patients over time to examine the risk factors associated with the development of FOG [4,5]. Findings from the DATATOP cohort suggested that the risk of developing FOG was significantly higher in more advanced PD

patients with predominant gait, balance, speech and bradykinetic motor symptoms rather than tremor dominant symptoms [5]. A more recent study also identified an akinetic-rigid phenotype as a primary risk factor for FOG along with lower education, not using a dopamine agonist and higher scores on the mood, cognitive disturbance and sleep disorder domains of the Hamilton Depression Rating Scale in a Chinese population when followed over 3 years [4].

Previous work has also reported that freezing is associated with cognitive dysfunction such as attentional set-shifting, conflict resolution and visuospatial processing [6-9]. Furthermore, research has shown that cognition declines at a faster rate in freezers compared to nonfreezers over a two-year period [10]. However, little research has disentangled whether these cognitive deficits precede the onset of FOG or whether cognitive decline accelerates after FOG develops. Affective disorders have also been linked to FOG [11] with both anxiety and depression being more common in freezers than non-freezers [12]. It is still debated whether these affective disturbances precede the onset and possibly contribute to the development of FOG or whether anxiety and depression arise as a result of developing FOG [13]. Finally, 
heterogeneity studies have highlighted an overlap between the non-tremor phenotype and rapid eye movement (REM) sleep behavior disorder (RBD) where patients experience dream enactment [14]. It has been postulated that the neuropathology underlying RBD may lie within the brainstem [15-17], an anatomical region that contains the pedunculopontine nucleus (PPN), a structure that is believed to play a critical role in gait function $[18,19]$. Work investigating patients with FOG has demonstrated that whilst RBD is associated with freezing in the early stages of disease, this relationship is not observed in advanced PD [15]. Thus, it remains unclear whether RBD might be useful to consider when predicting who might develop FOG in the future. Together, this body of evidence suggests that specific clinical symptoms may represent useful biomarkers for predicting the onset of FOG.

The objective of the current study was to create a more substantive predictive profile for transitional freezers by combining potential indicators of FOG from previously highlighted motor, cognitive, affective and sleep domains. The current study assessed three groups of PD participants, i) those who remained non-freezers over time, ii) those who developed FOG, and iii) those who continued to freeze. First, we sought to identify symptoms that preceded FOG then created a logistic regression model to predict those who would or would not develop FOG in the next year. Based on previous research, we hypothesized that in addition to obvious risk factors such as age and disease duration, a non-tremor dominant phenotype with executive dysfunction, greater affective disturbance and RBD might significantly predict the onset of FOG. 


\section{METHODS}

\section{Participants}

Longitudinal data was analyzed from 221 Parkinson's disease patients who attended the Parkinson's Disease Research Clinic at the Brain and Mind Centre, University of Sydney between 2008 and 2016. Ethical approval was obtained from the University of Sydney Human Research and Ethics Committee, and written informed consent obtained from each patient. Participant inclusion criteria included: a confirmed diagnosis of PD based on the UK

Brain Bank clinical criteria [20] by a trained neurologist (SJGL), and longitudinal data from at least two time points approximately 6-24 months apart. Patients were identified as freezers if they had responded positively on a validated screening instrument for identifying freezers, namely Item 3 of the Freezing of Gait-Questionnaire (FOG-Q3): "Do you feel that your feet get glued to the floor while walking, making a turn or when trying to initiate walking (freezing)?"[1,21]. Based on their response to FOG-Q3 at baseline and follow-up, participants were classified into three groups: non-freezers $(n=88)$ - those who reported 0 at both baseline and follow-up; transitional freezers $(n=41)$ - those who reported 0 at baseline and 1 or more at follow-up; and continuing freezers $(n=92)$ - those who reported 1 or more at both baseline and follow-up. All participants were assessed on their regular dose of medication.

\section{Motor, Cognitive, Limbic and Sleep Domains}

The Unified Parkinson's Disease Rating Scale motor subsection (UPDRS-III) assessed motor symptoms [22] with the exclusion of Question 3.11 ("Freezing of gait") [23]. A Tremor 
dominant (TD)/Non-TD phenotype ratio was also calculated [24,25]. The FOG-Questionnaire total (FOG-Q total) was used to assess global gait disturbance, however Item 3 was removed from the total, given that it was used to classify participants. Finally, dopamine dose equivalence (DDE) was also recorded when available.

Cognition was evaluated using the following measures: Digit Span (DS) Forward and Backward to examine attention and working memory, the Mini-Mental State Examination (MMSE) to measure global cognitive functioning, age-scaled Logical Memory (LM-I and II) retention scores to assess verbal memory, and the Trail Making Test parts A (TMT-A) and B (TMT-B) to assess psychomotor speed and attentional set-shifting ability, respectively $[26,27]$. Anxiety and depression were evaluated using the Hospital Anxiety and Depression Scale sub-scores (HADS-A \& D) [28]. Finally, RBD was evaluated using a sub-score of four questions (RBDSQ4) pertaining specifically to movements during REM sleep on the RBD Screening Questionnaire [29].

\section{( \\ Statistical analyses}

Linear mixed-effects models were employed to examine all variables longitudinally across all three groups. Age and disease duration were entered as covariates. Bonferroni post-hoc analyses were carried out to examine significant group effects and interactions. To further unpack the relationship between freezing of gait (frequency and severity) and cognitive and affective factors, correlational analyses were also carried out on baseline data (see Table 2).

A backwards stepwise (likelihood ratio) binary logistic regression was used to identify 
potential baseline predictors of FOG approximately one year before freezing onset (continuing freezers were excluded from this analysis). The dependent variable for the regression analysis was the presence or absence of FOG at follow-up. The independent variables included: the TD/non-TD ratio, FOG-Q total, UPDRS-III, TMT-A and TMT-B, DS-Forward, DS-Backward, LM-II, HADS-A and HADS-D, RBDSQ4, MMSE and age and disease duration at baseline. The stepwise method was chosen based on the exploratory nature of the study and a backwards model was employed to reduce the type II error rate. The significance level at which variables were entered and removed from the model was $p=0.05$ and $p=0.1$ respectively. The Homer and Lemeshow test was used to examine the goodness of fit for the model. Additionally, in effort to maximize clinical relevance, a post-hoc reduced factor model was constructed based the most significant predictive factors from the backwards logistic regression described above. The aim of this secondary analysis was to understand which tools could be implemented in clinical settings to detect those 'at-risk' for developing FOG and the success rate of these predictors. (1)

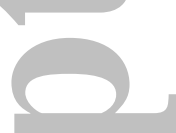

\section{RESULTS}

\section{Longitudinal Analyses}

Table 1 reports mean (SD) scores between groups and p-values for main effects and interactions from the linear mixed-effects models. Table 2 illustrates the relationship between freezing severity and cognitive and affective symptoms across all participants.

\section{Motor}


Overall group effects were found for DDE $[\mathrm{F}(2,105.18)=7.23, \mathrm{p}=0.001]$, UPDRS-III $[\mathrm{F}(2,213.97)=44.30, \mathrm{p}<0.001]$, and $\mathrm{TD} /$ non-TD ratio $[\mathrm{F}(2,216.84)=10.02, \mathrm{p}<0.001]$. Post hoc analyses revealed that non-freezers were receiving a lower dose of dopaminergic medication and had a lower symptom severity compared to the transitional and continuing freezers.

Continuing freezers also had significantly worse motor symptom severity compared to transitional freezers. Additionally, non-freezers had a significantly higher TD/non-TD ratio when compared to both freezer groups (indicating that freezers had a greater non-TD score). A main effect of time was also found for UPDRS-III $[\mathrm{F}(1,175.26)=4.11, \mathrm{p}=0.044]$, such that all PD patients had significantly worse symptom severity at follow-up compared to baseline.

A significant interaction between group and time was found for FOG-Q total $[F(2,218)=24.76, p<0.001]$. Post hoc analyses revealed that at baseline, continuing freezers had significantly worse gait severity than transitional freezers and non-freezers, but there was no difference between transitional freezers and non-freezers. However, at follow-up, transitional freezers had significantly more impaired gait than non-freezers. Continuing freezers continued to have the most severe gait impairment which was significantly greater than transitional freezers and non-freezers.

\section{Cognition}

Overall group effects were found for $\operatorname{MMSE}[\mathrm{F}(2,160.75)=16.72, \mathrm{p}<0.001]$, DS-Backwards $[\mathrm{F}(2,136.59)=6.63, \mathrm{p}=0.002]$ and TMT B-A $[\mathrm{F}(2,128.13)=6.17, \mathrm{p}=0.003]$. Post hoc analyses showed that there were no significant differences in performance on the MMSE, DSBackwards, or TMT B-A between transitional freezers and non-freezers. Transitional freezers performed significantly better on the MMSE compared to continuing freezers but were not 
different from continuing freezers on the DS-Backwards or TMT B-A. Continuing freezers performed significantly worse on the MMSE, DS-Backwards and TMT B-A compared to non-freezers. A main effect of time was found for $\operatorname{MMSE}[\mathrm{F}(1,123.17)=4.88, \mathrm{p}<0.001]$, LM-I and $\mathrm{II}[\mathrm{F}(1,120.36)=4.39, \mathrm{p}=0.038 ; \mathrm{F}(1,118.69)=14.54, \mathrm{p}<0.001]$, and TMT B-A

$[F(1,116.75)=4.05, p=0.046]$, which showed that whilst MMSE and TMT B-A scores got worse over time, scores for LM-I and II improved.

r

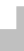

A significant interaction between group and time was found for TMT-B $[\mathrm{F}(2,119.21)=3.08$, $p=0.050]$. Post hoc analysis revealed that, at baseline, transitional freezers were not different from non-freezers nor continuing freezers. However, by follow-up, transitional freezers performed significantly worse on the TMT-B compared to non-freezers, and continuing freezers were significantly worse compared to transitional freezers and non-freezers. Thus, both freezing groups showed a significant increase in TMT-B scores at follow-up compared to baseline whereas the non-freezers did not change (Figure 1).

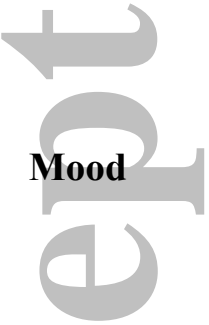

A group effect was found for HADS-A [F(2.209.99)=8.78, $\mathrm{p}<0.001]$ (Figure 2). Post hoc analyses revealed that both transitional freezers and the continuing freezers had significantly greater anxiety compared to non-freezers. A main effect of time was found for HADS-A $[\mathrm{F}(1,198.42)=56.27, \mathrm{p}<0.001]$, which revealed that anxiety worsened over time across all groups.

There was a significant interaction between group and time for $\operatorname{HADS}-\mathrm{D}[\mathrm{F}(2,200.30)=3.61$, $\mathrm{p}=0.029]$. Post hoc analyses showed that continuing freezers had significantly greater 
depression than transitional freezers and non-freezers at baseline, but were not different from transitional freezers at follow-up. Continuing freezers also reported significantly lower depression scores at follow-up compared to baseline.

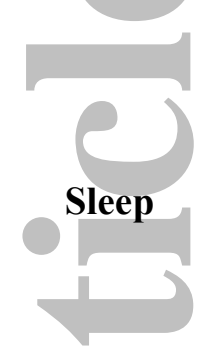

Overall group effects were found for RBDSQ4 $[F(2,215.50)=5.21, p=0.006]$. Post hoc analyses revealed that transitional freezers were not different from non-freezers or continuing freezers, however continuing freezers had significantly higher RBDSQ4 scores than nonfreezers.

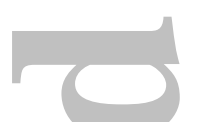

\section{Predictors of Freezing}

A model (see Table 3) was found to be a good fit for the data $\left(\chi^{2}(7)=5.91, p=0.55\right)$ which included 75 participants (52 non-freezers and 23 transitional freezers). The following predictors were included in the final model: age $(B=0.11, p=0.054)$, disease duration $(B=0.15, p=0.091), F O G-Q$ total $(B=0.85, p=0.01)$, the TD/non-TD ratio $(B=-1.60, p=0.085)$, TMT-B $(B=-0.02, p=0.055)$, HADS-A $(B=0.92, p=0.001)$, and HADS-D $(B=-0.32, p=0.067)$. The overall predictive success of the model was $84 \%$, and correctly classified $69.6 \%$ of transitional freezers and $90.4 \%$ of non-freezers.

Given that FOG-Q total and HADS-A were the strongest predictors in the above model, we examined the predictive power of using only these factors in effort to maximize clinical relevance. A model was found to be a good fit for the data $\left(\chi^{2}(8)=6.23, p=0.62\right)$ which 
included 117 participants (80 non-freezers and 37 transitional freezers). The model had an overall predictive success of $82.1 \%$, which correctly classified $64.9 \%$ of patients who developed FOG and $90 \%$ of patients who remained non-freezers. The following equation represents the probability (p) of developing FOG in the following year based on this

restricted model:

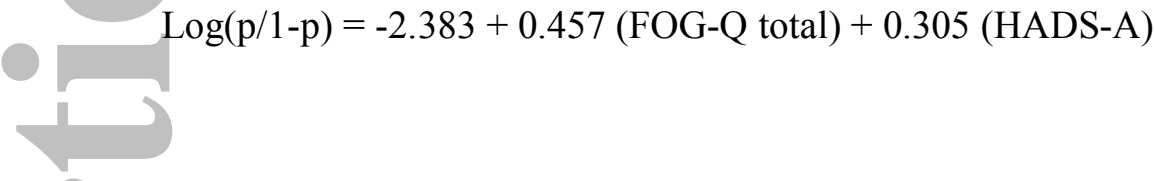

\section{DISCUSSION}

The overall aim of this study was to identify symptoms that preceded FOG, and create a predictive model that could be used to identify those 'at-risk' for developing freezing in the following year. Although there were many expected differences at baseline between freezers and non-freezers $[15,24]$, there were a few measures that differentiated between transitional freezers and non-freezers at baseline (i.e. one year prior to the onset of FOG). (1)

\section{Symptoms that precede FOG}

Motor aspects such as the DDE, UPDRS-III and a non-TD phenotype were found to be greater in transitional freezers (and continuing freezers) compared to non-freezers at baseline and follow-up. These findings are consistent with previous research showing that freezers have worse motor symptoms, especially non-tremor symptoms $[4,5,15,24,30]$. Such patients require greater dopaminergic therapy to manage these more severe symptoms $[31,32]$.

Anxiety was also greater in transitional freezers (and continuing freezers) compared to nonfreezers regardless of time point, which provides strong evidence that anxiety precedes the onset of FOG. These results are in support of previous work suggesting that anxiety is greater 
in freezers than non-freezers [12], and might be an important contributor to the underlying mechanism of FOG [33]. Depression however, was not significantly different in transitional freezers from non-freezers at baseline or follow-up, and therefore may not predict FOG onset. Nevertheless, continuing freezers had worse depression than transitional and non-freezers at baseline, which is similar to previous accounts [5,12]. Interestingly, depression levels in continuing freezers were reduced at follow-up compared to baseline and were no longer different from transitional freezers suggesting that this symptom was better managed by follow-up.

Surprisingly, there were no differences at baseline between transitional freezers and nonfreezers across the array of cognitive or sleep outcomes. Rather, once transitional freezers had developed FOG by follow-up, attentional set-shifting impairments (TMT-B) were found compared to non-freezers. Furthermore, only transitional freezers and continuing freezers (but not the non-freezer group) showed a significant decline in their set-shifting capabilities over time. Furthermore, the severity of FOG measured by the total score on the FOG-Q (including item 3) was associated with worsened cognition (regardless of neuropsychological assessment), greater affective symptom severity and greater RBD scores. Taken together, these findings might suggest that cognitive dysfunction and sleep disturbances either become gradually more impaired as FOG onset approaches as a function of disease progression, or that FOG onset, and impaired cognition and sleep occur within a similar timeframe because of shared neurobiological underpinnings such as cholinergic denervation within the pedunculopontine nucleus for example.

Predicting freezing of gait 
This study demonstrates that by examining specific symptoms (i.e. TD/non-TD ratio, FOG-Q total, TMT-B, anxiety, depression) along with age and disease duration, we could successfully predict with $84 \%$ accuracy those PD patients who transitioned to become a freezer and those who did not in the following year. The current findings are aligned with previous work $[4,5]$, which also showed that more severe gait disability, having a non-tremor dominant phenotype, as well as anxiety and depression were significant FOG risk factors.

Notably, the only domain that was not present in this model was sleep. Since RBD is generally considered a prodromal marker of PD, it may not be a useful indicator of later stage symptoms, such as freezing, despite biological overlap between RBD and FOG.

The ability to predict FOG has tremendous implications for patients, caregivers and clinicians, since it provides a unique opportunity to implement early therapeutic interventions to delay or even prevent the onset of FOG. This is likely to prolong patients' mobility and quality of life. For this reason, we also evaluated a more restricted model to predict FOG including simply two questionnaires that could be administered by a non-specialist. Although the predictive power was not as strong as the full model described above, by using only the FOG-Q total and the HADS-A score, we could predict whether one might develop FOG in the next year with $82.1 \%$ accuracy. It should be noted that this model is much better at classifying those who will not develop FOG (90\% accuracy), rather than those who will (65\% accuracy). Nonetheless, it may be a useful screening tool to identify individuals 'at-risk' who may need further assessment, such as comprehensive testing to improve predictive power, and could also identify candidates 'at-risk' or eligible for early intervention studies. Since $80 \%$ of patients will develop PD eventually, it is likely that a 1-year assessment is not enough and additional factors that were not measured here may also contribute to these prediction models. Thus, future research should consider flagging and following 'at-risk' individuals for 
a longer period, beyond the timeframe captured in this study to determine whether the predictive accuracy improves over time.

\section{Limitations and Clinical Implications}

A limitation of this study was the lack of DDE data for numerous participants, which led us to exclude DDE from the logistic regression. Since DDE is typically associated with disease duration and symptom severity, it might be expected to contribute in a similar way to these other variables that were included in the model. Alternatively, given that dopaminergic dysfunction may impact the degree to which network loops cross-over, dopamine agonists may play a crucial role in the development of FOG and may be a predictive factor worth exploring in future research. A second limitation that should be noted is that a subjective questionnaire was used to classify freezers, rather than an objective measure of freezing, which may be superior at detecting freezers and minimizing misclassification. In the current study, a video of FOG was not presented to participants prior to answering the FOG-Q, although many of the participants had clinically confirmed freezing, and continued to report FOG in subsequent visits. Nonetheless, future work should aim to utilize a video of FOG to minimize classification errors and if possible clinically confirm all participants who report FOG.

Despite these limitations, the findings from this study provide clinicians with means to better predict the likelihood that a patient will develop FOG. Future studies should focus on developing appropriate interventions with the goal of delaying or even halting the onset of FOG for those most at risk of transitioning. Current treatment options for FOG are very limited and hindered by inconsistent results [2], thus preventative measures may prove more 
effective. Cognitive training (CT) has been speculated to be a promising treatment for FOG [34]. Given that CT is targeted at improving executive functions in PD [35], it aims to promote the activation of compensatory networks and alleviate the cognitive interference that precedes FOG [34]. Alternatively, cholinesterase inhibitors might be used to target cognitive dysfunction preceding FOG onset. Research has linked FOG and neocortical cholinergic denervation [36], and has suggested cholinergic denervation as a potential mechanism underlying depression modulated cognitive impairment, which can exacerbate the cognitive symptoms found in PD [37]. Importantly, a recent review concluded that cholinesterase inhibitors can enhance cognitive function in PD patients with cognitive impairment [38], and have also shown to be promising for reducing falls in PD [39]. Thus further trials examining cholinesterase inhibitors are a much-needed undertaking [40]. Finally, given that anxiety is a strong predictor of FOG onset, anxiety should be targeted as part of prevention efforts for potential freezers, especially since to date, no randomized controlled trails have been undertaken to explore how anxiety management could delay the development or progression of FOG.

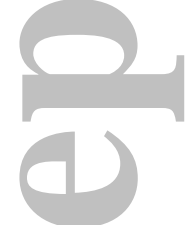

\section{CONCLUSION}

A careful assessment of selected symptoms can accurately predict the onset of FOG over a 15-month interval. These findings will hopefully allow future targeted treatments for FOG in PD, which would greatly enhance the quality of life for a substantial proportion of PD patients.

\section{ACKNOWLEDGEMENTS}


We are grateful to the research participants involved in this work.

\section{Authors' Roles}

1) Research project:

A. Conception: KEM, SJGL

B. Organization: KEM, MJG, MG, JMH, CCW, SJGL

C. Execution: KEM, ELL

2) Statistical Analysis:

A. Design: KEM, SJGL

B. Execution: KEM, ELL

C. Review and Critique; KEM, MJG, MG, JMH, CCW, SJGL

3) Manuscript:

A. Writing of the first draft: ELL

B. Review and Critique: KEM, MJG, MG, JMH, CCW, SJGL

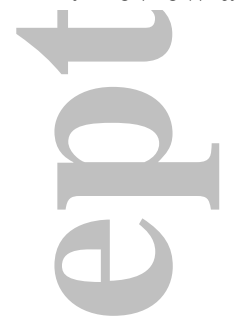

References

1 Giladi N, Treves TA, Simon ES, et al. Freezing of gait in patients with advanced Parkinson's disease. J Neural Transm 2001;108:53-61. doi:10.1007/s007020170096

2 Nonnekes J, Snijders AH, Nutt JG, et al. Freezing of gait: A practical approach to management. Lancet Neurol 2015;14:768-78. doi:10.1016/S1474-4422(15)00041-1

3 Macht M, Kaussner Y, Möller JC, et al. Predictors of freezing in Parkinson's disease: A survey of 6,620 patients. Mov Disord 2007;22:953-6. doi:10.1002/mds.21458

4 Zhang $\mathrm{H}$, Yin X, Ouyang Z, et al. A prospective study of freezing of gait with early 
Parkinson disease in Chinese patients. Medicine (Baltimore) 2016;95:e4056. doi:10.1097/MD.0000000000004056 Giladi N, McDermott MP, Fahn S, et al. Freezing of gait in PD: prospective assessment in the DATATOP cohort. Neurology 2001;56:1712-21.

doi:10.1212/WNL.56.12.1712

6 Naismith SL, Shine JM, Lewis SJG. The specific contributions of set-shifting to freezing of gait in Parkinson's disease. Mov Disord 2010;25:1000-4. doi:10.1002/mds.23005

7 Amboni M, Cozzolino A, Longo K, et al. Freezing of gait and executive functions in patients with Parkinson's disease. Mov Disord 2008;23:395-400.

8 Walton CC, Shine JM, Mowszowski L, et al. Impaired cognitive control in Parkinson's disease patients with freezing of gait in response to cognitive load. $J$ Neural Transm 2015;122:653-60.

9 Walton CC, O'Callaghan C, Hall JM, et al. Antisaccade errors reveal cognitive control deficits in Parkinson's disease with freezing of gait. J Neurol 2015;262:2745-54. doi:10.1007/s00415-015-7910-5

10 Amboni M, Barone P, Picillo M, et al. A two-year follow-up study of executive dysfunctions in parkinsonian patients with freezing of gait at on-state. Mov Disord 2010;25:800-2.

11 Lieberman A. Are freezing of gait (FOG) and panic related? J Neurol Sci 2006;248:219-22. doi:10.1016/j.jns.2006.05.023

12 Ehgoetz Martens KA, Hall JM, Gilat M, et al. Anxiety is associated with freezing of gait and attentional set-shifting in Parkinson's disease: A new perspective for early intervention. Gait Posture 2016;49:431-6. doi:10.1016/j.gaitpost.2016.07.182

13 Ehgoetz Martens KA, Ellard CG, Almeida QJ. Evaluating the Link Between 
Dopaminergic Treatment, Gait Impairment, and Anxiety in Parkinson's Disease. Mov Disord Clin Pract Published Online First: 2016. doi:10.1002/mdc3.12298

14 Kumru H, Santamaria J, Tolosa E, et al. Relation between subtype of Parkinson's disease and REM sleep behavior disorder. Sleep Med 2007;8:779-83.

doi:10.1016/j.sleep.2007.02.005

15 Hall JM, Shine JM, O'Callaghan C, et al. Freezing of gait and its associations in the early and advanced clinical motor stages of Parkinson's disease: A cross-sectional study. J Park Dis 2015.

16 Postuma RB, Gagnon J-F, Vendette M, et al. Manifestations of Parkinson disease differ in association with REM sleep behavior disorder. Mov Disord 2008;23:1665-72. doi:10.1002/mds.22099

17 Romenets SR, Gagnon J-F, Latreille V, et al. Rapid eye movement sleep behavior disorder and subtypes of Parkinson's disease. Mov Disord 2012;27:996-1003. doi: $10.1002 / \mathrm{mds} .25086$

18 Lau B, Welter ML, Belaid H, et al. The integrative role of the pedunculopontine nucleus in human gait. Brain 2015;138:1284-96. doi:10.1093/brain/awv047

19 Windels F, Thevathasan W, Silburn P, et al. Where and what is the PPN and what is its role in locomotion? Brain 2015;128:1133-4.

20 Hughes AJ, Daniel SE, Kilford L, et al. Accuracy of clinical diagnosis of idiopathic Parkinson's disease: a clinico-pathological study of 100 cases. J Neurol Neurosurg Psychiatry 1992;55:181-4. doi:10.1136/JNNP.55.3.181

21 Shine JM, Moore ST, Bolitho SJ, et al. Assessing the utility of Freezing of Gait Questionnaires in Parkinson's Disease. Parkinsonism Relat Disord 2012;18:25-9. doi:10.1016/j.parkreldis.2011.08.002

22 Goetz CG, Tilley BC, Shaftman SR, et al. Movement Disorder Society-sponsored 
revision of the Unified Parkinson's Disease Rating Scale (MDS-UPDRS): Scale presentation and clinimetric testing results. Mov Disord 2008;23:2129-70.

doi:10.1002/mds. 22340

23 Georgiades MJ, Gilat M, Ehgoetz Martens KA, et al. Investigating motor initiation and inhibition deficits in patients with Parkinson's disease and freezing of gait using a virtual reality paradigm. Neuroscience 2016;337:153-62.

doi:10.1016/j.neuroscience.2016.09.019

24 Hall JM, Shine JM, Walton CC, et al. Early phenotypic differences between Parkinson's disease patients with and without freezing of gait. Park Relat Disord 2014;20:604-7. doi:10.1016/j.parkreldis.2014.02.028

25 Lewis SJG, Foltynie T, Blackwell AD, et al. Heterogeneity of Parkinson's disease in the early clinical stages using a data driven approach. J Neurol Neurosurg Psychiatry 2005;76:343-8. doi:10.1136/jnnp.2003.033530

26 Reitan R, Wolfson D. The Halstead-Reitan neuropsychological test battery: Theory and clinical interpretation. 1985.

27 Wechsler D. Wechsler memory scale (WMS-III). San Antonio, TX: Psychological Corporation.: 1997.

28 Zigmond AS, Snaith RP. The Hospital Anxiety and Depression Scale. Acta Psychiatr Scand 1983;67:361-70. doi:10.1111/j.1600-0447.1983.tb09716.x

29 Bolitho SJ, Naismith SL, Terpening Z, et al. Investigating rapid eye movement sleep without atonia in Parkinson's disease using the rapid eye movement sleep behavior disorder screening questionnaire. Mov Disord 2014;29:736-42.

doi: $10.1002 / \mathrm{mds} .25832$

30 Factor SA, Steenland NK, Higgins DS, et al. Postural instability/gait disturbance in Parkinson's disease has distinct subtypes: an exploratory analysis. J Neurol Neurosurg 
Psychiatry 2011;82:564-8. doi:10.1136/jnnp.2010.222042

31 Vervoort G, Bengevoord A, Strouwen C, et al. Progression of postural control and gait deficits in Parkinson's disease and freezing of gait: A longitudinal study. Parkinsonism Relat Disord 2016;28:73-9. doi:10.1016/j.parkreldis.2016.04.029

32 Gray P, Hildebrand K. Fall Risk Factors in Parkinson's Disease. J Neurosci Nurs 2000;32:222-8.

33 Ehgoetz Martens KA, Ellard CG, Almeida QJ, et al. Does Anxiety Cause Freezing of Gait in Parkinson's Disease? PLoS One 2014;9:e106561.

doi:10.1371/journal.pone.0106561

34 Walton CC, Shine JM, Mowszowski L, et al. Freezing of gait in Parkinson's disease: Current treatments and the potential role for cognitive training. Restor Neurol

Neurosci 2014;32:411-22. doi:10.3233/RNN-130370

35 Leung IHK, Walton CC, Hallock H, et al. Cognitive training in Parkinson disease A systematic review and meta-analysis. Neurology 2015;85:1843-51.

36 Bohnen NI, Frey KA, Studenski S, et al. Extra-nigral pathological conditions are common in Parkinson's disease with freezing of gait: An in vivo positron emission tomography study. Mov Disord 2014;29:1118-24. doi:10.1002/mds.25929

37 Bohnen NI, Albin RL. The cholinergic system and Parkinson disease. Behav Brain Res 2011;221:564-73. doi:10.1016/j.bbr.2009.12.048

38 Wang H-F, Yu J-T, Tang S-W, et al. Efficacy and safety of cholinesterase inhibitors and memantine in cognitive impairment in Parkinson's disease, Parkinson's disease dementia, and dementia with Lewy bodies: systematic review with meta-analysis and trial sequential analysis. J Neurol Neurosurg Psychiatry 2015;86:135-43.

doi:10.1136/jnnp-2014-307659

39 Chung KA, Lobb BM, Nutt JG, et al. Effects of a central cholinesterase inhibitor on 
reducing falls in Parkinson disease. Neurology 2010;75:1263-9.

doi:10.1212/WNL.0b013e3181f6128c

40 Fling BW, Cohen RG, Mancini M, et al. Functional reorganization of the locomotor network in Parkinson patients with freezing of gait. PLoS One 2014;9:e100291.

doi:10.1371/journal.pone.0100291

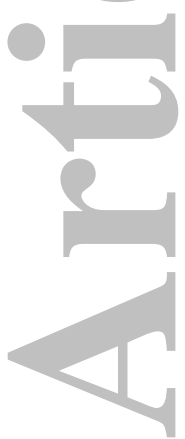

Figure Legend

Figure 1. Transitional freezers showed greater deficits in set-shifting compared to nonfreezers at follow-up but not baseline.

Figure 2. Transitional freezers and continuing freezers had greater anxiety compared to non-

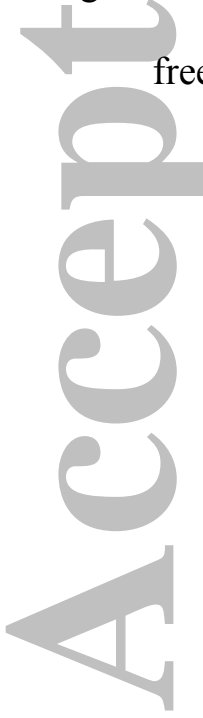

John Wiley \& Sons

This article is protected by copyright. All rights reserved. 


\section{Predicting the onset of freezing of gait: A Longitudinal study}

Kaylena A. Ehgoetz Martens ${ }^{1}$, PhD, Emily L. Lukasik ${ }^{1}$, MBMSc, Matthew J. Georgiades ${ }^{1}$, BSc, Moran Gilat ${ }^{1}$, MSc, Julie M. Hall ${ }^{1,2}$, MSc, Courtney C. Walton ${ }^{1}$, BSc (Hons), Simon J.G. Lewis ${ }^{1}$, MD, NHMRC, PhD

${ }^{1}$ Parkinson's Disease Research Clinic, Brain and Mind Centre, University of Sydney ${ }^{2}$ School of Social Sciences and Psychology, Western Sydney University

Corresponding Author:

Kaylena A. Ehgoetz Martens

Parkinson's Disease Research Clinic, Brain and Mind Centre, University of Sydney

100 Mallet Street, New South Wales, 2050

Phone +610293510870

kaylena.ehgoetzmartens@sydney.edu.au

Running Title: Anxiety is a predictor of FOG onset

Word count paper: 2968

Number of references: 30

Number of tables: 2

Number of figures: 3

Keywords: Parkinson's disease, freezing of gait, cognition, anxiety, motor, sleep

Author Disclosures: Kaylena A. Ehgoetz Martens - Reports no disclosures; Emily L. Lukasik

- Reports no disclosures; Matthew J. Georgiades - Reports no disclosures;Moran Gilat -

Reports no disclosures; Julie M. Hall - Reports no disclosures; Courtney C. Walton -

Reports no disclosures; Simon J.G. Lewis - Reports no disclosures

This work was supported by funding to Forefront, a collaborative research group dedicated to the study of non-Alzheimer disease degenerative dementias, from the National Health and Medical Research Council of Australia program grant (\#1037746 and \#1095127). Kaylena A. Ehgoetz Martens is supported by a Parkinson Canada Postdoctoral fellowship. Matthew J.

Georgiades is supported by the Sydney Medical School RA Money Postgraduate Research Scholarship in Neuroscience. Moran Gilat is supported by a University of Sydney 
International Scholarship. Julie M. Hall is supported by a Western Sydney University Postgraduate Research Award. These funding organizations did not play any role in the design and conductor of the study; collection, management, analysis or interpretation of the data; nor the preparation, review, approval of the manuscript, or decision to submit the manuscript for publication.
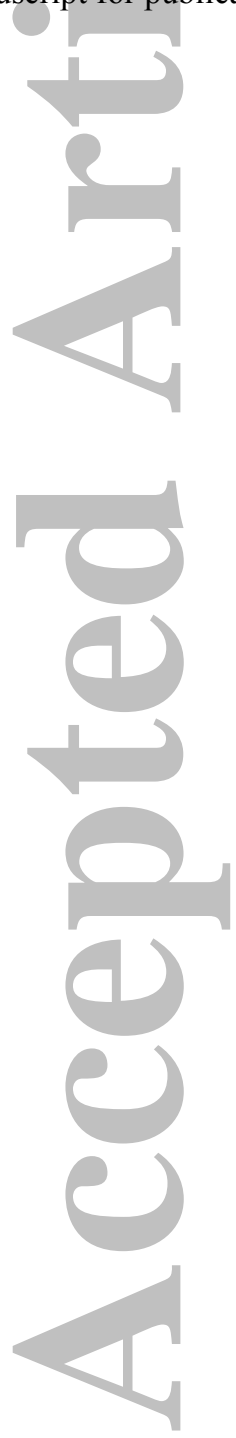


\begin{abstract}
Objective: Freezing of gait (FOG) is a disabling symptom of Parkinson's disease (PD) that ultimately affects approximately $80 \%$ of patients, yet very little research has focused on predicting the onset of FOG and tracking the longitudinal progression of symptoms prior to its onset. The objective of the current study was to examine longitudinal data spanning the transition period where patients with PD developed FOG to identify symptoms that may precede freezing and create a prediction model that identifies those 'at risk' for developing FOG in the year to follow.

Methods: Two-hundred and twenty-one patients with PD were divided into three groups (88 non-freezers, 41 transitional-freezers, and 92 continuing-freezers) based on their responses to the validated FOG-Questionnaire Item 3 at baseline and follow-up. Critical measures across motor, cognitive, mood and sleep domains were assessed at two time points approximately one year apart.

Results: A logistic regression model which included age, disease duration, gait symptoms, motor phenotype, attentional set-shifting, and mood measures could predict with $70 \%$ and $90 \%$ accuracy, respectively those patients who would and would not develop FOG over the next year. Notably, the FOG-Questionnaire total and the Anxiety section of the Hospital Anxiety and Depression Scale were the strongest predictors, and alone, could significantly predict if one might develop FOG in the next 15 months with $82 \%$ accuracy.
\end{abstract}

Conclusions: Our results suggest that it is possible to identify the majority of patients who will develop FOG in the following year potentially allowing targeted interventions to delay or possibly even prevent the onset of freezing. 


\section{INTRODUCTION}

Freezing of gait (FOG) is a common and complex symptom in Parkinson's disease (PD) with a poorly understood onset [1] and limited options for successful treatment [2]. Whilst approximately $80 \%$ of patients ultimately develop FOG [3], predicting who and when is currently not possible, thus thwarting targeted interventions.

To date, only two studies have followed early stage PD patients over time to examine the risk factors associated with the development of FOG [4,5]. Findings from the DATATOP cohort suggested that the risk of developing FOG was significantly higher in more advanced PD patients with predominant gait, balance, speech and bradykinetic motor symptoms rather than tremor dominant symptoms [5]. A more recent study also identified an akinetic-rigid phenotype as a primary risk factor for FOG along with lower education, not using a dopamine agonist and higher scores on the mood, cognitive disturbance and sleep disorder domains of the Hamilton Depression Rating Scale in a Chinese population when followed over 3 years [4].

Previous work has also reported that freezing is associated with cognitive dysfunction such as attentional set-shifting, conflict resolution and visuospatial processing [6-9]. Furthermore, research has shown that cognition declines at a faster rate in freezers compared to nonfreezers over a two-year period [10]. However, little research has disentangled whether these cognitive deficits precede the onset of FOG or whether cognitive decline accelerates after FOG develops. Affective disorders have also been linked to FOG [11] with both anxiety and depression being more common in freezers than non-freezers [12]. It is still debated whether these affective disturbances precede the onset and possibly contribute to the development of FOG or whether anxiety and depression arise as a result of developing FOG [13]. Finally, 
heterogeneity studies have highlighted an overlap between the non-tremor phenotype and rapid eye movement (REM) sleep behavior disorder (RBD) where patients experience dream enactment [14]. It has been postulated that the neuropathology underlying RBD may lie within the brainstem [15-17], an anatomical region that contains the pedunculopontine nucleus (PPN), a structure that is believed to play a critical role in gait function $[18,19]$. Work investigating patients with FOG has demonstrated that whilst RBD is associated with freezing in the early stages of disease, this relationship is not observed in advanced PD [15]. Thus, it remains unclear whether RBD might be useful to consider when predicting who might develop FOG in the future. Together, this body of evidence suggests that specific clinical symptoms may represent useful biomarkers for predicting the onset of FOG.

The objective of the current study was to create a more substantive predictive profile for transitional freezers by combining potential indicators of FOG from previously highlighted a motor, cognitive, affective and sleep domains. The current study assessed three groups of PD participants, i) those who remained non-freezers over time, ii) those who developed FOG, and iii) those who continued to freeze. First, we sought to identify symptoms that preceded FOG then created a logistic regression model to predict those who would or would not develop FOG in the next year. Based on previous research, we hypothesized that in addition to obvious risk factors such as age and disease duration, a non-tremor dominant phenotype with executive dysfunction, greater affective disturbance and RBD might significantly predict the onset of FOG.

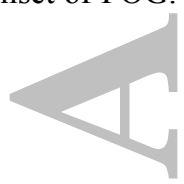




\section{METHODS}

\section{Participants}

Longitudinal data was analyzed from 221 Parkinson's disease patients who attended the Parkinson's Disease Research Clinic at the Brain and Mind Centre, University of Sydney between 2008 and 2016. Ethical approval was obtained from the University of Sydney Human Research and Ethics Committee, and written informed consent obtained from each patient. Participant inclusion criteria included: a confirmed diagnosis of PD based on the UK Brain Bank clinical criteria [20] by a trained neurologist (SJGL), and longitudinal data from at least two time points approximately 6-24 months apart. Patients were identified as freezers if they had responded positively on a validated screening instrument for identifying freezers, namely Item 3 of the Freezing of Gait-Questionnaire (FOG-Q3): "Do you feel that your feet get glued to the floor while walking, making a turn or when trying to initiate walking (freezing)?"[1,21]. Based on their response to FOG-Q3 at baseline and follow-up, participants were classified into three groups: non-freezers $(\mathrm{n}=88)-$ those who reported 0 at both baseline and follow-up; transitional freezers $(n=41)$ - those who reported 0 at baseline and 1 or more at follow-up; and continuing freezers $(n=92)$ - those who reported 1 or more at both baseline and follow-up. All participants were assessed on their regular dose of medication.

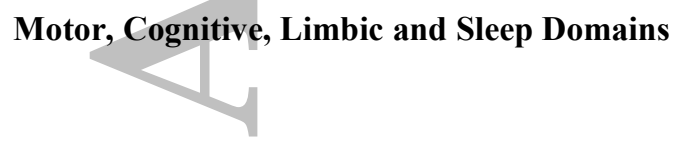

The Unified Parkinson's Disease Rating Scale motor subsection (UPDRS-III) assessed motor symptoms [22] with the exclusion of Question 3.11 ("Freezing of gait") [23]. A Tremor 
dominant (TD)/Non-TD phenotype ratio was also calculated [24,25]. The FOG-Questionnaire total (FOG-Q total) was used to assess global gait disturbance, however Item 3 was removed from the total, given that it was used to classify participants. Finally, dopamine dose equivalence (DDE) was also recorded when available.

Cognition was evaluated using the following measures: Digit Span (DS) Forward and Backward to examine attention and working memory, the Mini-Mental State Examination (MMSE) to measure global cognitive functioning, age-scaled Logical Memory (LM-I and II) retention scores to assess verbal memory, and the Trail Making Test parts A (TMT-A) and B (TMT-B) to assess psychomotor speed and attentional set-shifting ability, respectively [26,27]. Anxiety and depression were evaluated using the Hospital Anxiety and Depression Scale sub-scores (HADS-A \& D) [28]. Finally, RBD was evaluated using a sub-score of four questions (RBDSQ4) pertaining specifically to movements during REM sleep on the RBD Screening Questionnaire [29].

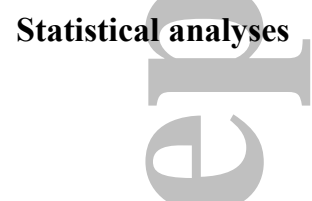

Linear mixed-effects models were employed to examine all variables longitudinally across all three groups. Age and disease duration were entered as covariates. Bonferroni post-hoc analyses were carried out to examine significant group effects and interactions. To further unpack the relationship between freezing of gait (frequency and severity) and cognitive and affective factors, correlational analyses were also carried out on baseline data (see Table 2).

Furthermore, a $\underline{\mathrm{A}}$ backwards stepwise (likelihood ratio) binary logistic regression was used to 
identify potential baseline predictors of FOG approximately one year before freezing onset (continuing freezers were excluded from this analysis). The dependent variable for the regression analysis was the presence or absence of FOG at follow-up. The independent variables included: the TD/non-TD ratio, FOG-Q total, UPDRS-III, TMT-A and TMT-B, DS-Forward, DS-Backward, LM-II, HADS-A and HADS-D, RBDSQ4, MMSE and age and disease duration at baseline. The stepwise method was chosen based on the exploratory nature of the study and a backwards model was employed to reduce the type II error rate. The significance level at which variables were entered and removed from the model was $\mathrm{p}=0.05$ and $\mathrm{p}=0.1$ respectively. The Homer and Lemeshow test was used to examine the goodness of fit for the model. Additionally, in effort to maximize clinical relevance, a post-hoc reduced factor model was constructed based the most significant predictive factors from the backwards logistic regression described above. The aim of this secondary analysis was to understand which tools could be implemented in clinical settings to detect those 'at-risk' for (a) developing FOG and the success rate of these predictors.

RESULTS<smiles>[C]1CCC1</smiles>

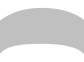

r

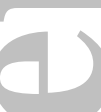

Longitudinal Analyses

Table 1 reports mean (SD) scores between groups and p-values for main effects and interactions from the linear mixed-effects models. Table 2 illustrates the relationship between freezing severity and cognitive and affective symptoms across all participants.

\section{Motor}


Overall group effects were found for $\operatorname{DDE}[\mathrm{F}(2,105.18)=7.23, \mathrm{p}=0.001]$, UPDRS-III $[F(2,213.97)=44.30, p<0.001]$, and $T D /$ non- $T D$ ratio $[F(2,216.84)=10.02, p<0.001]$. Post hoc analyses revealed that non-freezers were receiving a lower dose of dopaminergic medication and had a lower symptom severity compared to the transitional and continuing freezers. Continuing freezers also had significantly worse motor symptom severity compared to transitional freezers. Additionally, non-freezers had a significantly higher TD/non-TD ratio when compared to both freezer groups (indicating that freezers had a greater non-TD score). A main effect of time was also found for UPDRS-III $[F(1,175.26)=4.11, p=0.044]$, such that all PD patients had significantly worse symptom severity at follow-up compared to baseline.

A significant interaction between group and time was found for FOG-Q total $[F(2,218)=24.76, p<0.001]$. Post hoc analyses revealed that at baseline, continuing freezers had significantly worse gait severity than transitional freezers and non-freezers, but there was no difference between transitional freezers and non-freezers. However, at follow-up, transitional freezers had significantly more impaired gait than non-freezers. Continuing freezers continued to have the most severe gait impairment which was significantly greater than transitional freezers and non-freezers.

\section{Cognition}

Overall group effects were found for MMSE $[\mathrm{F}(2,160.75)=16.72, \mathrm{p}<0.001]$, DS-Backwards $[F(2,136.59)=6.63, p=0.002]$ and TMT B-A $[F(2,128.13)=6.17, p=0.003]$. Post hoc analyses showed that there were no significant differences in performance on the MMSE, DS-

Backwards, or TMT B-A between transitional freezers and non-freezers. Transitional freezers performed significantly better on the MMSE compared to continuing freezers but were not 
different from continuing freezers on the DS-Backwards or TMT B-A. Continuing freezers performed significantly worse on the MMSE, DS-Backwards and TMT B-A compared to non-freezers. A main effect of time was found for $\operatorname{MMSE}[\mathrm{F}(1,123.17)=4.88, \mathrm{p}<0.001]$, LM-I and II $[\mathrm{F}(1,120.36)=4.39, \mathrm{p}=0.038 ; \mathrm{F}(1,118.69)=14.54, \mathrm{p}<0.001]$, and TMT B-A $[\mathrm{F}(1,116.75)=4.05, \mathrm{p}=0.046]$, which showed that whilst MMSE and TMT B-A scores got worse over time, scores for LM-I and II improved.

A significant interaction between group and time was found for TMT-B $[\mathrm{F}(2,119.21)=3.08$, $\mathrm{p}=0.050]$. Post hoc analysis revealed that, at baseline, transitional freezers were not different from non-freezers nor continuing freezers. However, by follow-up, transitional freezers performed significantly worse on the TMT-B compared to non-freezers, and continuing freezers were significantly worse compared to transitional freezers and non-freezers. Thus, both freezing groups showed a significant increase in TMT-B scores at follow-up compared to baseline whereas the non-freezers did not change (Figure 1).

\section{Mood}
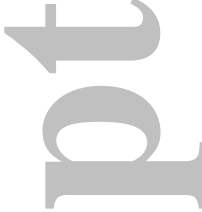

A group effect was found for HADS-A $[F(2.209 .99)=8.78, p<0.001]$ (Figure 2). Post hoc analyses revealed that both transitional freezers and the continuing freezers had significantly greater anxiety compared to non-freezers. A main effect of time was found for HADS-A (

$[F(1,198.42)=56.27, \mathrm{p}<0.001]$, which revealed that anxiety worsened over time across all

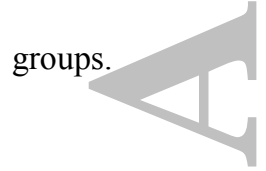

There was a significant interaction between group and time for HADS-D $[F(2,200.30)=3.61$, $\mathrm{p}=0.029]$. Post hoc analyses showed that continuing freezers had significantly greater 
depression than transitional freezers and non-freezers at baseline, but were not different from transitional freezers at follow-up. Continuing freezers also reported significantly lower depression scores at follow-up compared to baseline.

Sleep

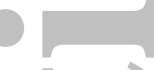

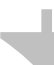

Overall group effects were found for RBDSQ4 $[F(2,215.50)=5.21, p=0.006]$. Post hoc analyses revealed that transitional freezers were not different from non-freezers or continuing freezers, however continuing freezers had significantly higher RBDSQ4 scores than nonfreezers.

\section{Predictors of Freezing}

\section{1}

A model (see Table $\underline{3} z$ ) was found to be a good fit for the data $\left(\chi^{2}(7)=5.91, p=0.55\right)$ which included 75 participants (52 non-freezers and 23 transitional freezers). The following predictors were included in the final model: age $(\mathrm{B}=0.11, \mathrm{p}=0.054)$, disease duration $(\mathrm{B}=0.15, \mathrm{p}=0.091)$, FOG-Q total $(\mathrm{B}=0.85, \mathrm{p}=0.01)$, the $\mathrm{TD} /$ non-TD ratio $(\mathrm{B}=-1.60, \mathrm{p}=0.085)$, TMT-B $(B=-0.02, p=0.055)$, HADS-A $(B=0.92, p=0.001)$, and HADS-D $(B=-0.32, p=0.067)$. The overall predictive success of the model was $84 \%$, and correctly classified $69.6 \%$ of transitional freezers and $90.4 \%$ of non-freezers.

Given that FOG-Q total and HADS-A were the strongest predictors in the above model, we examined the predictive power of using only these factors in effort to maximize clinical relevance. A model was found to be a good fit for the data $\left(\chi^{2}(8)=6.23, \mathrm{p}=0.62\right)$ which 
included 117 participants ( 80 non-freezers and 37 transitional freezers). The model had an overall predictive success of $82.1 \%$, which correctly classified $64.9 \%$ of patients who developed FOG and $90 \%$ of patients who remained non-freezers. The following equation represents the probability (p) of developing FOG in the following year based on this restricted model:

$\log (\mathrm{p} / 1-\mathrm{p})=-2.383+0.457($ FOG-Q total $)+0.305($ HADS-A $)$

\section{DISCUSSION}

The overall aim of this study was to identify symptoms that preceded FOG, and create a predictive model that could be used to identify those 'at-risk' for developing freezing in the following year. Although there were many expected differences at baseline between freezers and non-freezers [15,24], there were a few measures that differentiated between transitional freezers and non-freezers at baseline (i.e. one year prior to the onset of FOG).

\section{Symptoms that precede FOG}

Motor aspects such as the DDE, UPDRS-III and a non-TD phenotype were found to be greater in transitional freezers (and continuing freezers) compared to non-freezers at baseline and follow-up. These findings are consistent with previous research showing that freezers have worse motor symptoms, especially non-tremor symptoms $[4,5,15,24,30]$. Such patients require greater dopaminergic therapy to manage these more severe symptoms $[31,32]$. Anxiety was also greater in transitional freezers (and continuing freezers) compared to nonfreezers regardless of time point, which provides strong evidence that anxiety precedes the onset of FOG. These results are in support of previous work suggesting that anxiety is greater 
in freezers than non-freezers [12], and might be an important contributor to the underlying mechanism of FOG [33]. Depression however, was not significantly different in transitional freezers from non-freezers at baseline or follow-up, and therefore may not predict FOG onset. Nevertheless, continuing freezers had worse depression than transitional and non-freezers at baseline, which is similar to previous accounts [5,12]. Interestingly, depression levels in continuing freezers were reduced at follow-up compared to baseline and were no longer different from transitional freezers suggesting that this symptom was better managed by follow-up.

Surprisingly, there were no differences at baseline between transitional freezers and nonfreezers across the array of cognitive or sleep outcomes. Rather, once transitional freezers had developed FOG by follow-up, attentional set-shifting impairments (TMT-B) were found compared to non-freezers. Furthermore, only transitional freezers and continuing freezers $(0)$ (but not the non-freezer group) showed a significant decline in their set-shifting capabilities over time. Furthermore, the severity of FOG measured by the total score on the FOG-Q (including item 3) was associated with worsened cognition (regardless of neuropsychological assessment), greater affective symptom severity and greater RBD scores. Taken together, This these findings might suggest that cognitive dysfunction and sleep disturbances eithersetshifting either becomes gradually more impaired as FOG onset approaches as a function of disease progression, or that FOG onset, and and-impaired cognition and sleep-set-shifting occur within a similar timeframe because of shared neurobiological underpinnings such as cholinergic denervation within the pedunculopontine nucleus for example. In support of this notion, transitional freezers and continuing freezers had similar performance on TMT B-A as well as DS Backwards regardless of time. 
Predicting freezing of gait

This study demonstrates that by examining specific symptoms (i.e. TD/non-TD ratio, FOG-Q total, TMT-B, anxiety, depression) along with age and disease duration, we could successfully predict with $84 \%$ accuracy those PD patients who transitioned to become a freezer and those who did not in the following year. The current findings are aligned with previous work $[4,5]$, which also showed that more severe gait disability, having a non-tremor dominant phenotype, as well as anxiety and depression were significant FOG risk factors. Notably, the only domain that was not present in this model was sleep. Since RBD is generally considered a prodromal marker of PD, it may not be a useful indicator of later stage symptoms, such as freezing, despite biological overlap between RBD and FOG.

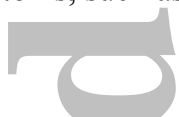

The ability to predict FOG has tremendous implications for patients, caregivers and clinicians, since it provides a unique opportunity to implement early therapeutic interventions to delay or even prevent the onset of FOG. This is likely to prolong patients' mobility and quality of life. For this reason, we also evaluated a more restricted model to predict FOG including simply two questionnaires that could be administered by a non-specialist. Although the predictive power was not as strong as the full model described above, by using only the FOG-Q total and the HADS-A score, we could predict whether one might develop FOG in the next year with $82.1 \%$ accuracy. It should be noted that this model is much better at classifying those who will not develop FOG (90\% accuracy), rather than those who will (65\% accuracy). Nonetheless, it may be a useful screening tool to identify individuals 'at-risk' who may need further assessment, such as comprehensive testing to improve predictive power, and could also identify candidates 'at-risk' or eligible for early intervention studies. $\underline{\text { Since }}$ $\underline{80 \% \text { of patients will develop PD eventually, it is likely that a 1-year assessment is not enough }}$ 
and additional factors that were not measured here may also contribute to these prediction models. Thus, Future future research should consider flagging and following 'at-risk' individuals for a longer period, beyond the timeframe captured in this study to determine whether the predictive accuracy improves over time.

\section{Limitations and Clinical Implications}

A limitation of this study was the lack of DDE data for numerous participants, which led us to exclude DDE from the logistic regression. Since DDE is typically associated with disease duration and symptom severity, it might be expected to contribute in a similar way to these other variables that were included in the model. Alternatively, gGiven that dopaminergic dysfunction may impact the degree to which network loops cross-over, dopamine agonists may play a crucial role in the development of FOG and may be a predictive factor worth exploring in future research. A second limitation that should be noted is that a subjective questionnaire was used to classify freezers, rather than an objective measure of freezing, which may be superior at detecting freezers and minimizing misclassification. In the current study, a video of FOG was not presented to participants prior to answering the FOG-Q, although many of the participants had clinically confirmed freezing, and continued to report FOG in subsequent visits. Nonetheless, future work should aim to utilize a video of FOG to minimize classification errors and if possible clinically confirm all participants who report $\underline{\text { FOG. }}$

Despite these limitations, the findings from this study provide clinicians with means to better predict the likelihood that a patient will develop FOG. Future studies should focus on developing appropriate interventions with the goal of delaying or even halting the onset of

Formatted: Font: Not Bold Formatted: Font: Not Bold, Not Italic Formatted: Font: Not Bold Formatted: Font: Not Bold, Not Italic Formatted: Font: Not Bold Formatted: Font: Not Bold, Not Italic Formatted: Font: Not Bold 
FOG for those most at risk of transitioning. Current treatment options for FOG are very limited and hindered by inconsistent results [2], thus preventative measures may prove more effective. Cognitive training (CT) has been speculated to be a promising treatment for FOG [34]. Given that CT is targeted at improving executive functions in $\mathrm{PD}$ [35], it aims to promote the activation of compensatory networks and alleviate the cognitive interference that precedes FOG [34]. Alternatively, cholinesterase inhibitors might be used to target cognitive dysfunction preceding FOG onset. Research has linked FOG and neocortical cholinergic denervation [36], and has suggested cholinergic denervation as a potential mechanism underlying depression modulated cognitive impairment, which can exacerbate the cognitive symptoms found in PD [37]. Importantly, a recent review concluded that cholinesterase inhibitors can enhance cognitive function in PD patients with cognitive impairment [38], and have also shown to be promising for reducing falls in PD [39]. Thus further trials examining cholinesterase inhibitors are a much-needed undertaking [40]. Finally, given that anxiety is a strong predictor of FOG onset, anxiety should be targeted as part of prevention efforts for potential freezers, especially since to date, no randomized controlled trails have been undertaken to explore how anxiety management could delay the development or progression of FOG.

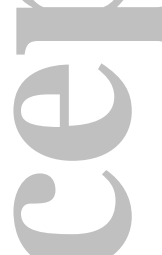

\section{CONCLUSION}

A careful assessment of selected symptoms can accurately predict the onset of FOG over a 15-month interval. These findings will hopefully allow future targeted treatments for FOG in PD, which would greatly enhance the quality of life for a substantial proportion of PD patients. 


\section{ACKNOWLEDGEMENTS}

We are grateful to the research participants involved in this work.

\section{Authors' Roles}

1) Research project:

A. Conception: KEM, SJGL

B. Organization: KEM, MJG, MG, JMH, CCW, SJGL

C. Execution: KEM, ELL

2) Statistical Analysis:

A. Design: KEM, SJGL

B. Execution: KEM, ELL

C. Review and Critique; KEM, MJG, MG, JMH, CCW, SJGL

3) Manuscript:

A. Writing of the first draft: ELL

B. Review and Critique: KEM, MJG, MG, JMH, CCW, SJGL

\section{References}

1 Giladi N, Treves TA, Simon ES, et al. Freezing of gait in patients with advanced Parkinson's disease. J Neural Transm 2001;108:53-61. doi:10.1007/s007020170096

2 Nonnekes J, Snijders AH, Nutt JG, et al. Freezing of gait: A practical approach to management. Lancet Neurol 2015;14:768-78. doi:10.1016/S1474-4422(15)00041-1

3 Macht M, Kaussner Y, Möller JC, et al. Predictors of freezing in Parkinson's disease: 
A survey of 6,620 patients. Mov Disord 2007;22:953-6. doi:10.1002/mds.21458

Zhang H, Yin X, Ouyang Z, et al. A prospective study of freezing of gait with early

Parkinson disease in Chinese patients. Medicine (Baltimore) 2016;95:e4056.

doi:10.1097/MD.0000000000004056

Giladi N, McDermott MP, Fahn S, et al. Freezing of gait in PD: prospective ro assessment in the DATATOP cohort. Neurology 2001;56:1712-21.

doi:10.1212/WNL.56.12.1712

Naismith SL, Shine JM, Lewis SJG. The specific contributions of set-shifting to freezing of gait in Parkinson's disease. Mov Disord 2010;25:1000-4.

doi: $10.1002 / \mathrm{mds} .23005$

Amboni M, Cozzolino A, Longo K, et al. Freezing of gait and executive functions in patients with Parkinson's disease. Mov Disord 2008;23:395-400.

Walton CC, Shine JM, Mowszowski L, et al. Impaired cognitive control in Parkinson's disease patients with freezing of gait in response to cognitive load. $J$ Neural Transm 2015;122:653-60.

Walton CC, O'Callaghan C, Hall JM, et al. Antisaccade errors reveal cognitive control deficits in Parkinson's disease with freezing of gait. J Neurol 2015;262:2745-54.

doi:10.1007/s00415-015-7910-5

Amboni M, Barone P, Picillo M, et al. A two-year follow-up study of executive dysfunctions in parkinsonian patients with freezing of gait at on-state. Mov Disord 2010;25:800-2.

Lieberman A. Are freezing of gait (FOG) and panic related? J Neurol Sci 2006;248:219-22. doi:10.1016/j.jns.2006.05.023

Ehgoetz Martens KA, Hall JM, Gilat M, et al. Anxiety is associated with freezing of gait and attentional set-shifting in Parkinson's disease: A new perspective for early 
intervention. Gait Posture 2016;49:431-6. doi:10.1016/j.gaitpost.2016.07.182

Ehgoetz Martens KA, Ellard CG, Almeida QJ. Evaluating the Link Between

Dopaminergic Treatment, Gait Impairment, and Anxiety in Parkinson's Disease. Mov

Disord Clin Pract Published Online First: 2016. doi:10.1002/mdc3.12298

Kumru H, Santamaria J, Tolosa E, et al. Relation between subtype of Parkinson's

disease and REM sleep behavior disorder. Sleep Med 2007;8:779-83.

doi:10.1016/j.sleep.2007.02.005

Hall JM, Shine JM, O'Callaghan C, et al. Freezing of gait and its associations in the early and advanced clinical motor stages of Parkinson's disease: A cross-sectional study. J Park Dis 2015.

Postuma RB, Gagnon J-F, Vendette M, et al. Manifestations of Parkinson disease differ in association with REM sleep behavior disorder. Mov Disord 2008;23:1665-72. doi:10.1002/mds.22099

Romenets SR, Gagnon J-F, Latreille V, et al. Rapid eye movement sleep behavior disorder and subtypes of Parkinson's disease. Mov Disord 2012;27:996-1003.

doi: $10.1002 / \mathrm{mds} .25086$

Lau B, Welter ML, Belaid $\mathrm{H}$, et al. The integrative role of the pedunculopontine nucleus in human gait. Brain 2015;138:1284-96. doi:10.1093/brain/awv047

Windels F, Thevathasan W, Silburn P, et al. Where and what is the PPN and what is its role in locomotion? Brain 2015;128:1133-4.

Hughes AJ, Daniel SE, Kilford L, et al. Accuracy of clinical diagnosis of idiopathic Parkinson's disease: a clinico-pathological study of 100 cases. J Neurol Neurosurg Psychiatry 1992;55:181-4. doi:10.1136/JNNP.55.3.181

Shine JM, Moore ST, Bolitho SJ, et al. Assessing the utility of Freezing of Gait Questionnaires in Parkinson's Disease. Parkinsonism Relat Disord 2012;18:25-9. 
doi:10.1016/j.parkreldis.2011.08.002

Goetz CG, Tilley BC, Shaftman SR, et al. Movement Disorder Society-sponsored revision of the Unified Parkinson's Disease Rating Scale (MDS-UPDRS): Scale presentation and clinimetric testing results. Mov Disord 2008;23:2129-70.

doi:10.1002/mds. 22340

Georgiades MJ, Gilat M, Ehgoetz Martens KA, et al. Investigating motor initiation and inhibition deficits in patients with Parkinson's disease and freezing of gait using a virtual reality paradigm. Neuroscience 2016;337:153-62.

doi:10.1016/j.neuroscience.2016.09.019

Hall JM, Shine JM, Walton CC, et al. Early phenotypic differences between Parkinson's disease patients with and without freezing of gait. Park Relat Disord 2014;20:604-7. doi:10.1016/j.parkreldis.2014.02.028

Lewis SJG, Foltynie T, Blackwell AD, et al. Heterogeneity of Parkinson's disease in the early clinical stages using a data driven approach. J Neurol Neurosurg Psychiatry 2005;76:343-8. doi:10.1136/jnnp.2003.033530

Reitan R, Wolfson D. The Halstead-Reitan neuropsychological test battery: Theory and clinical interpretation. 1985.

Wechsler D. Wechsler memory scale (WMS-III). San Antonio, TX: Psychological Corporation.: 1997.

Zigmond AS, Snaith RP. The Hospital Anxiety and Depression Scale. Acta Psychiatr Scand 1983;67:361-70. doi:10.1111/j.1600-0447.1983.tb09716.x

Bolitho SJ, Naismith SL, Terpening Z, et al. Investigating rapid eye movement sleep without atonia in Parkinson's disease using the rapid eye movement sleep behavior disorder screening questionnaire. Mov Disord 2014;29:736-42.

doi:10.1002/mds. 25832 
Factor SA, Steenland NK, Higgins DS, et al. Postural instability/gait disturbance in Parkinson's disease has distinct subtypes: an exploratory analysis. J Neurol Neurosurg Psychiatry 2011;82:564-8. doi:10.1136/jnnp.2010.222042

Vervoort G, Bengevoord A, Strouwen C, et al. Progression of postural control and gait deficits in Parkinson's disease and freezing of gait: A longitudinal study. Parkinsonism Relat Disord 2016;28:73-9. doi:10.1016/j.parkreldis.2016.04.029

Gray P, Hildebrand K. Fall Risk Factors in Parkinson's Disease. J Neurosci Nurs $2000 ; 32: 222-8$.

Ehgoetz Martens KA, Ellard CG, Almeida QJ, et al. Does Anxiety Cause Freezing of

Gait in Parkinson's Disease? PLoS One 2014;9:e106561.

doi:10.1371/journal.pone.0106561

Walton CC, Shine JM, Mowszowski L, et al. Freezing of gait in Parkinson's disease:

Current treatments and the potential role for cognitive training. Restor Neurol

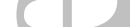

Neurosci 2014;32:411-22. doi:10.3233/RNN-130370

Leung IHK, Walton CC, Hallock H, et al. Cognitive training in Parkinson disease A systematic review and meta-analysis. Neurology 2015;85:1843-51.

Bohnen NI, Frey KA, Studenski S, et al. Extra-nigral pathological conditions are common in Parkinson's disease with freezing of gait: An in vivo positron emission tomography study. Mov Disord 2014;29:1118-24. doi:10.1002/mds.25929

Bohnen NI, Albin RL. The cholinergic system and Parkinson disease. Behav Brain Res 2011;221:564-73. doi:10.1016/j.bbr.2009.12.048

Wang H-F, Yu J-T, Tang S-W, et al. Efficacy and safety of cholinesterase inhibitors and memantine in cognitive impairment in Parkinson's disease, Parkinson's disease dementia, and dementia with Lewy bodies: systematic review with meta-analysis and trial sequential analysis. J Neurol Neurosurg Psychiatry 2015;86:135-43. 
doi:10.1136/jnnp-2014-307659

Chung KA, Lobb BM, Nutt JG, et al. Effects of a central cholinesterase inhibitor on reducing falls in Parkinson disease. Neurology 2010;75:1263-9.

doi:10.1212/WNL.0b013e3181f6128c

40 Fling BW, Cohen RG, Mancini M, et al. Functional reorganization of the locomotor network in Parkinson patients with freezing of gait. PLoS One 2014;9:e100291.

doi:10.1371/journal.pone.0100291

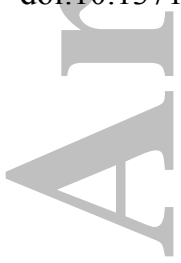

Figure Legend

Figure 1. Transitional freezers showed greater deficits in set-shifting compared to nonfreezers at follow-up but not baseline.

Figure 2. Transitional freezers and continuing freezers had greater anxiety compared to nonfreezers at baseline and follow-up.

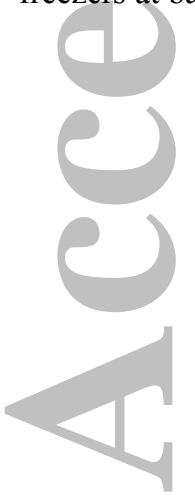




\begin{tabular}{|c|c|c|c|c|c|c|c|c|c|}
\hline & \multicolumn{5}{|c|}{ Group } & & \multirow{3}{*}{ Group Effect } & \multirow{3}{*}{ Time Effect } & \multirow{3}{*}{$\begin{array}{l}\text { Group*Time } \\
\text { Interaction }\end{array}$} \\
\hline F & & & \multicolumn{2}{|c|}{ Transitional Freezers } & \multicolumn{2}{|c|}{ Continuing Freezers } & & & \\
\hline Time point & 1 & 2 & 1 & 2 & 1 & 2 & & & \\
\hline $\mathrm{N}$ & \multicolumn{2}{|c|}{88} & \multicolumn{2}{|c|}{41} & \multicolumn{2}{|c|}{92} & & & \\
\hline $\begin{array}{l}\text { Time between } \\
\text { baseline and follow- } \\
\text { up (months) }\end{array}$ & \multicolumn{2}{|c|}{$14.8 \pm 4.6$} & \multicolumn{2}{|c|}{$15 \pm 4.6$} & \multicolumn{2}{|c|}{$12.8 \pm 4.6$} & & & \\
\hline Male/Female & \multicolumn{2}{|c|}{$52 / 36$} & \multicolumn{2}{|c|}{$26 / 15$} & \multicolumn{2}{|c|}{$56 / 36$} & & & \\
\hline Age (years) & \multicolumn{2}{|c|}{$65.37 \pm 9.84$} & \multicolumn{2}{|c|}{$70.75 \pm 9.39$} & \multicolumn{2}{|c|}{$70.24 \pm 10.85$} & \multicolumn{2}{|l|}{$\mathrm{p}=0.002 *$} & \\
\hline $\begin{array}{l}\text { Disease duration } \\
\text { (vears) }\end{array}$ & \multicolumn{2}{|c|}{$3.16 \pm 4.32$} & \multicolumn{2}{|c|}{$5.97 \pm 4.14$} & \multicolumn{2}{|c|}{$9.66 \pm 7.50$} & $\mathrm{p}<0.001^{*}$ & & \\
\hline DDE & $\begin{array}{l}504.77 \pm \\
355.21\end{array}$ & $\begin{array}{l}584.49 \pm \\
293.34\end{array}$ & $\begin{array}{l}832.15 \pm \\
452.28\end{array}$ & $\begin{array}{l}992.33 \pm \\
422.81\end{array}$ & $\begin{array}{l}909.92 \pm \\
549.31\end{array}$ & $\begin{array}{l}804.57 \pm \\
478.61\end{array}$ & $\mathrm{p}<0.001 *$ & $\mathrm{p}=0.49$ & $\mathrm{P}=0.271$ \\
\hline MDS-UPDRS III & $\begin{array}{l}24.51 \\
\pm 13.62\end{array}$ & $\begin{array}{l}25.51 \pm \\
14.40\end{array}$ & $35.14 \pm 17.07$ & $38.42 \pm 15.33$ & $48.64 \pm 20.68$ & $49.81 \pm 21.06$ & $\mathrm{p}<0.001 *$ & $\mathrm{p}=0.044 *$ & $\mathrm{P}=0.539$ \\
\hline TD/non-TD ratio & $0.80 \pm 0.82$ & $0.65 \pm 0.54$ & $0.51 \pm 0.36$ & $0.48 \pm 0.39$ & $0.45 \pm 0.43$ & $0.37 \pm 0.32$ & $\mathrm{p}<0.001^{*}$ & $\mathrm{p}=0.055$ & $\mathrm{P}=0.624$ \\
\hline FOG-Q total & $1.41 \pm 1.37$ & $1.68 \pm 1.60$ & $2.68 \pm 1.74$ & $6.17 \pm 2.39$ & $10.23 \pm 4.19$ & $10.79 \pm 4.02$ & $\mathrm{p}<0.001 *$ & $\mathrm{p}<0.001^{*}$ & $\mathrm{p}<0.001^{*}$ \\
\hline MMSE & $28.60 \pm 1.78$ & $28.65 \pm 2.17$ & $28.45 \pm 1.93$ & $27.39 \pm 2.92$ & $26.58 \pm 3.50$ & $24.89 \pm 5.53$ & $\mathrm{p}<0.001^{*}$ & $\mathrm{p}=0.029^{*}$ & $\mathrm{P}=0.053$ \\
\hline Digit Span Forward & $10.18 \pm 2.51$ & $10.59 \pm 2.49$ & $10.42 \pm 1.90$ & $9.96 \pm 1.81$ & $9.41 \pm 2.33$ & $9.70 \pm 2.21$ & $\mathrm{p}=0.106$ & $\mathrm{p}=0.69$ & $\mathrm{P}=0.282$ \\
\hline $\begin{array}{l}\text { Digit Span } \\
\text { Backwards }\end{array}$ & $6.98 \pm 1.76$ & $7.19 \pm 1.94$ & $6.30 \pm 1.69$ & $6.40 \pm 2.18$ & $5.92 \pm 2.03$ & $5.97 \pm 1.72$ & $\mathrm{p}=0.002 *$ & $\mathrm{p}=0.493$ & $\mathrm{P}=0.861$ \\
\hline TMT A (sec) & $\begin{array}{l}39.75 \\
\pm 19.36\end{array}$ & $38.40 \pm 33.75$ & $43.03 \pm 20.73$ & $46.18 \pm 23.65$ & $47.90 \pm 20.74$ & $50.43 \pm 29.15$ & $\mathrm{p}=0.084$ & $\mathrm{p}=0.424$ & $\mathrm{P}=0.591$ \\
\hline TMT B (sec) & $\begin{array}{l}96.99 \\
\pm 77.25\end{array}$ & $87.70 \pm 49.39$ & $\begin{array}{l}117.93 \\
\pm 65.42\end{array}$ & $\begin{array}{l}139.54 \\
\pm 102.67\end{array}$ & $\begin{array}{l}131.03 \\
\pm 81.06\end{array}$ & $\begin{array}{l}149.50 \\
\pm 93.69\end{array}$ & $\mathrm{p}=0.005^{*}$ & $\mathrm{p}=0.014^{*}$ & $\mathrm{P}=.050^{*}$ \\
\hline TMT B-A (sec) & $\begin{array}{l}56.94 \\
\pm 62.38\end{array}$ & $49.67 \pm 34.18$ & $74.90 \pm 53.98$ & $93.57 \pm 85.08$ & $83.64 \pm 68.77$ & $99.08 \pm 71.77$ & $\mathrm{p}=0.003^{*}$ & $\mathrm{p}=0.046^{*}$ & $\mathrm{P}=0.102$ \\
\hline Logical memory 1 & $9.79 \pm 2.74$ & $10.62 \pm 3.27$ & $10.54 \pm 3.83$ & $10.04 \pm 3.51$ & $8.13 \pm 3.25$ & $9.81 \pm 3.40$ & $\mathrm{p}=0.007 *$ & $\mathrm{p}=0.038^{*}$ & $\mathrm{P}=0.07$ \\
\hline Logical memory 2 & $10.32 \pm 3.33$ & $10.92 \pm 3.18$ & $10.81 \pm 3.45$ & $11.60 \pm 3.20$ & $9.03 \pm 3.08$ & $10.81 \pm 3.31$ & $\mathrm{p}=0.159$ & $\mathrm{p}<0.001^{*}$ & $\mathrm{P}=0.426$ \\
\hline HADS A & $1.18 \pm 2.31$ & $3.62 \pm 2.93$ & $3.65 \pm 3.08$ & $5.18 \pm 4.68$ & $2.94 \pm 3.89$ & $5.38 \pm 4.19$ & $\mathrm{p}<0.001^{*}$ & $\mathrm{p}<0.001^{*}$ & $\mathrm{P}=0.526$ \\
\hline HADS D & $4.10 \pm 3.80$ & $3.54 \pm 3.45$ & $6.14 \pm 4.80$ & $5.31 \pm 4.14$ & $8.96 \pm 5.48$ & $6.61 \pm 4.20$ & $\mathrm{p}<0.001^{*}$ & $\mathrm{p}<0.001^{*}$ & $\mathrm{P}=0.029^{*}$ \\
\hline RBDSQ4 & $1.64 \pm 2.02$ & $1.84 \pm 2.02$ & $2.23 \pm 2.35$ & $2.73 \pm 2.29$ & $2.69 \pm 2.30$ & $2.63 \pm 2.12$ & $\mathrm{P}=0.006^{*}$ & $\mathrm{P}=0.077$ & $\mathrm{P}=0.279$ \\
\hline
\end{tabular}


Mean scores \pm standard deviation are presented. * indicates significant effects. Abbreviations: $N F$ Non-Freezer, $T F$ Transitional Freezer, $C F$ Continuing Freezer, $D D E$ Dopamine Dose Equivalence, MDS-UPDRS The Movement Disorder Society-Unified Parkinson's Disease Rating Scale, TD Tremor Dominant, $F O G$ - $Q$ Freezing of Gait Questionnaire, $M M S E$ Mini Mental State Examination, $T M T(A \& B, B-A)$ Trail Making Test parts A \& B; Part B-Part A, HADS (A, D) Hospital Anxiety and Depression Scale (Anxiety, Depression sub-scores, RBDSQ REM Sleep Behavior Disorder Questionnaire.

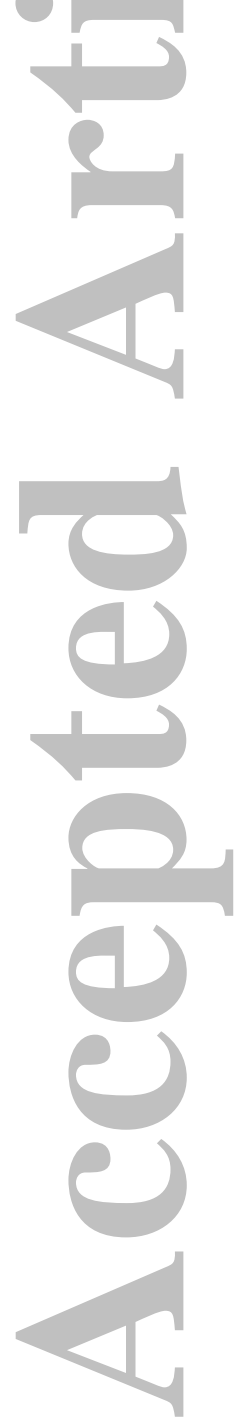




\begin{tabular}{|c|c|}
\hline & $\begin{array}{c}\text { FOGQ-Total } \\
\text { (severity) }\end{array}$ \\
\hline MMSE & $-0.409^{* *}$ \\
\hline TMT-A & $-0.288^{* *}$ \\
\hline TMT-B & $-0.218^{*}$ \\
\hline Digit Span Forwards & $-0.232 * *$ \\
\hline Digit Span Backwards & $\begin{array}{l}-0.245^{* *} \\
-0.305 * *\end{array}$ \\
\hline LM-I & $-0.305^{* *}$ \\
\hline LM-II & $-0.272 * *$ \\
\hline HADS-A & $0.206^{* *}$ \\
\hline HADS-D & $0.499 * *$ \\
\hline RBDSQ4 & $0.185^{* *}$ \\
\hline
\end{tabular}

John Wiley \& Sons

This article is protected by copyright. All rights reserved. 
Table 3. Motor and non-motor predictors of freezing of gait

\begin{tabular}{lllll} 
& & \multicolumn{3}{c}{$95 \%$ CI for Odds Ratio } \\
\cline { 3 - 5 } & \multirow{2}{*}{ B (SE) } & Lower & Odds Ratio & Upper \\
\hline Age & $0.11(0.06)$ & 0.10 & 1.11 & 1.24 \\
Disease Duration & $0.15(0.09)$ & 0.98 & 1.16 & 1.39 \\
TD/non-TD ratio & $-1.60(0.93)$ & 0.03 & 0.20 & 1.24 \\
FOG-Q total & $0.85 *(0.33)$ & 1.23 & 2.34 & 4.45 \\
TMT B raw score & $-0.02(0.01)$ & 0.97 & 0.99 & 1.00 \\
HADS A & $0.92 *(0.28)$ & 1.46 & 2.50 & 4.30 \\
HADS D & $-0.32(0.17)$ & 0.52 & 0.73 & 1.02 \\
Constant & $-7.94 *(3.58)$ & & & \\
\hline
\end{tabular}

$R^{2}=0.45\left(\right.$ Cox \& Snell), $R^{2}=0.64$ (Nagelkerke). Homer and Lemeshow

Goodness of fit $\chi^{2}(7)=5.83, p=0.56$. *indicates Wald statistic $p<.05$.

TD: Tremor Dominant, FOG-Q: Freezing of Gait Questionnaire, TMT: Trail Making Test, HADS A and D: Hospital Anxiety and Depression Scale anxiety and depression sub-scores.

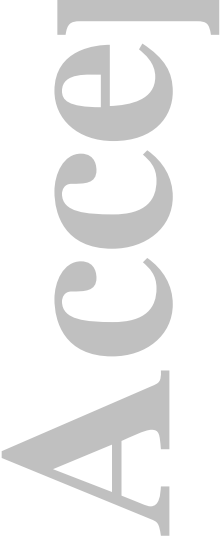

John Wiley \& Sons

This article is protected by copyright. All rights reserved. 


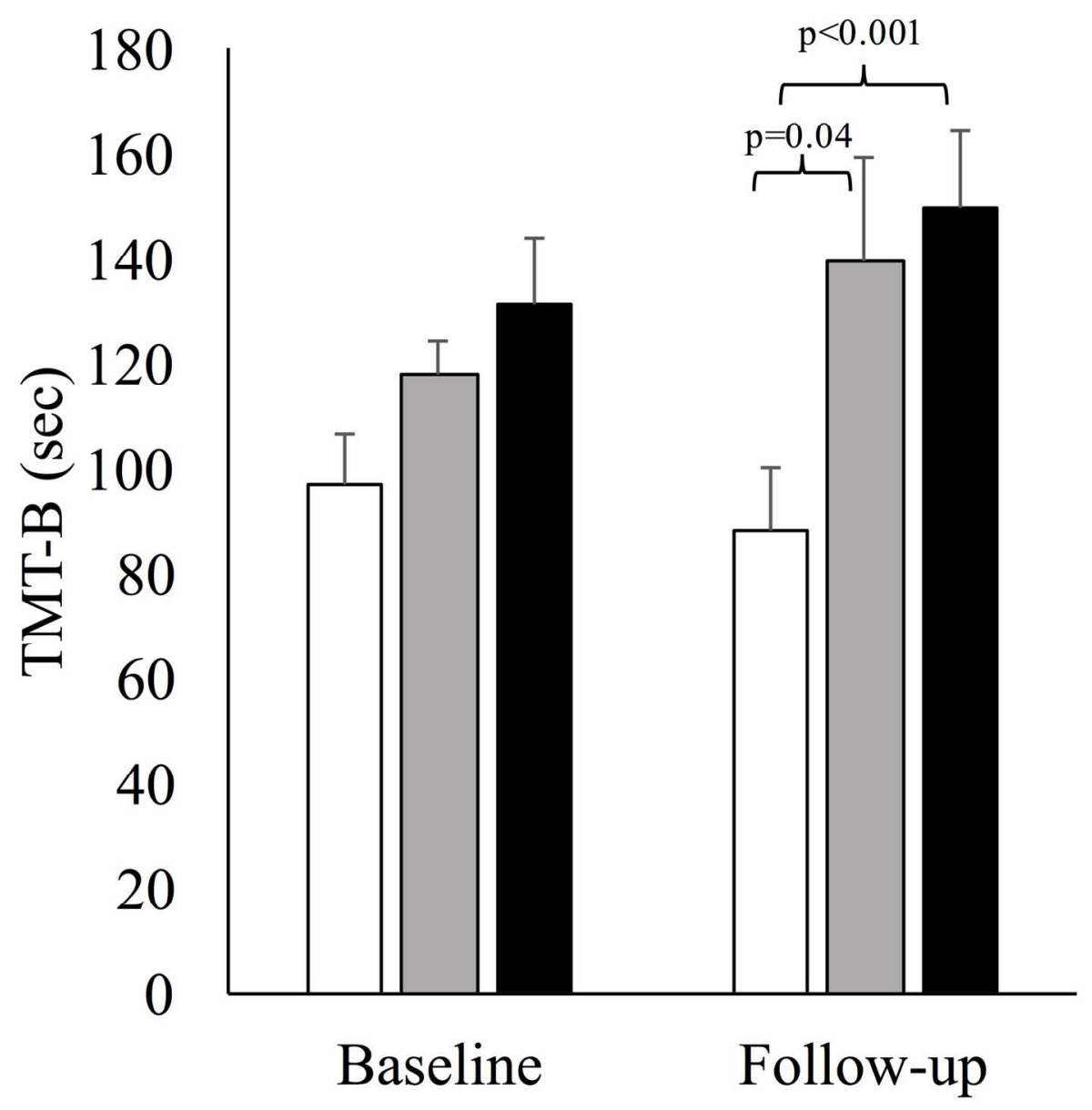

$\square$ Non-Freezers

$\square$ Transitional Freezers

- Continuing Freezers

Figure 1. Transitional freezers showed greater deficits in set-shifting compared to non-freezers at follow-up but not baseline.

$150 \times 183 \mathrm{~mm}(300 \times 300 \mathrm{DPI})$

John Wiley \& Sons

This article is protected by copyright. All rights reserved. 


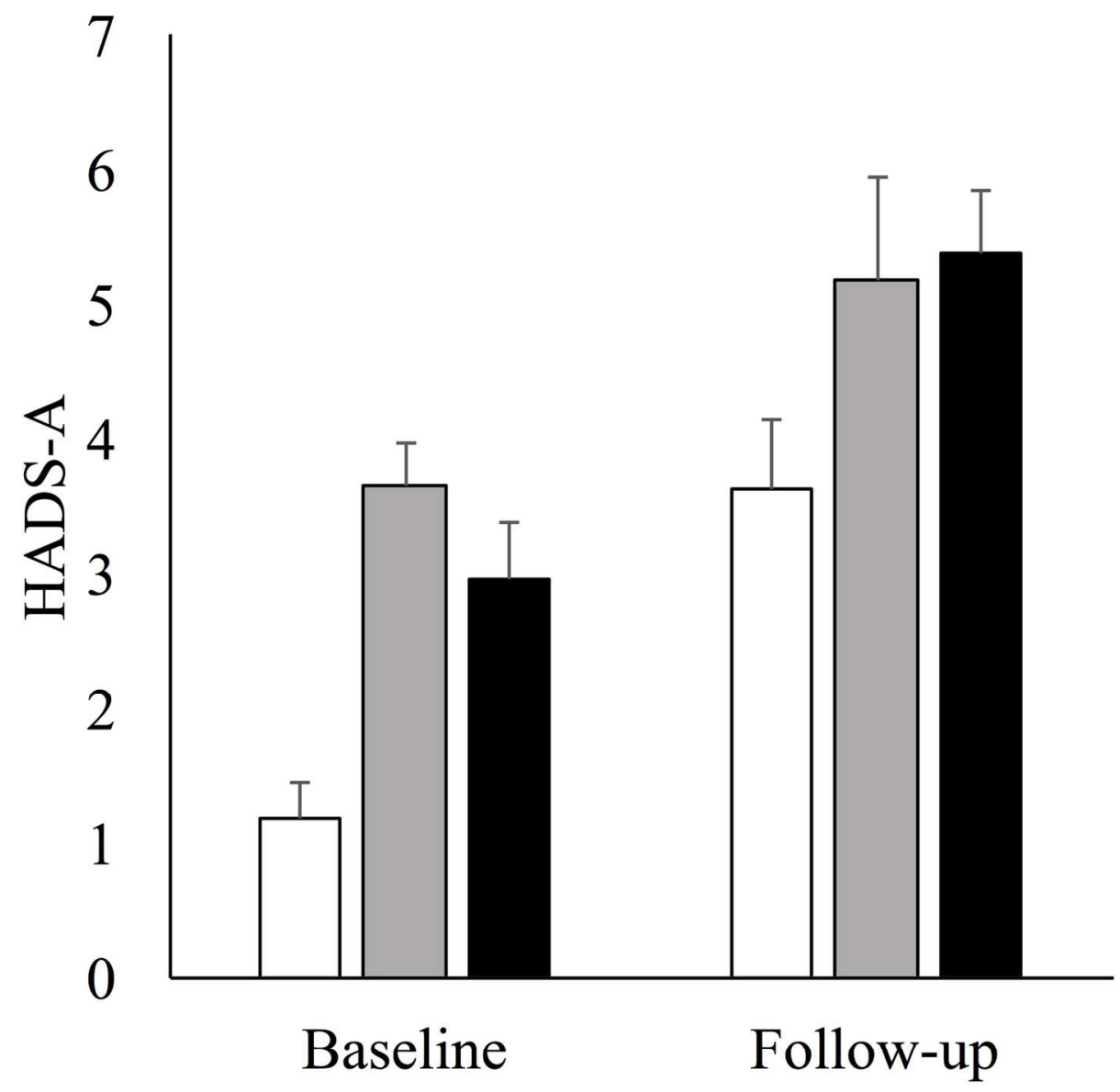

$\square$ Non-Freezers

$\square$ Transitional Freezers

- Continuing Freezers

Figure 2. Transitional freezers and continuing freezers had greater anxiety compared to non-freezers at baseline and follow-up.

$150 \times 178 \mathrm{~mm}(300 \times 300 \mathrm{DPI})$

John Wiley \& Sons

This article is protected by copyright. All rights reserved. 


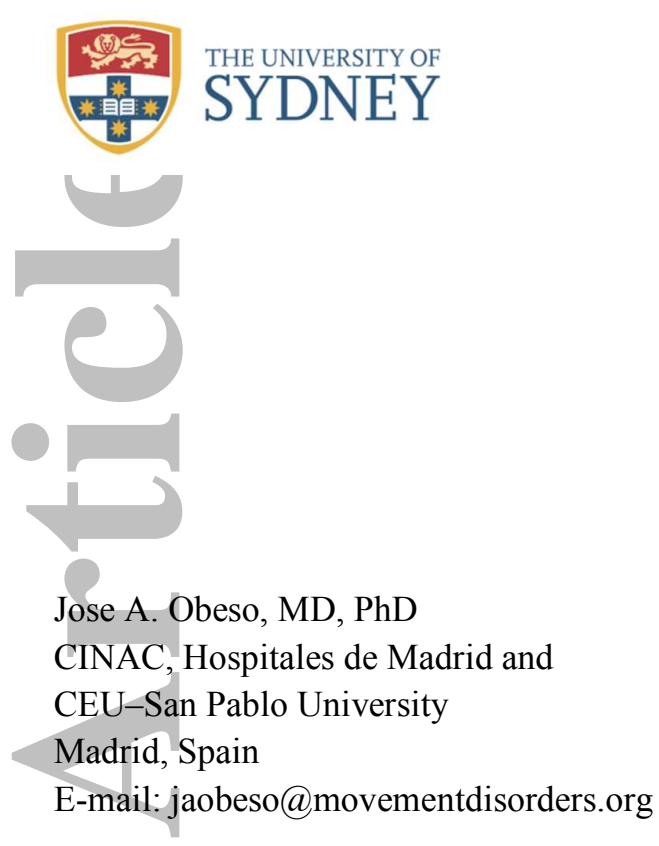

\section{Brain and Mind Centre}

Parkinson's Disease Research Clinic Level 2, 94 Mallett St CAMPERDOWN NSW 2050

AUSTRALIA

Telephone: +61293510702

Web: www.sydney.edu.au/brain-mind/

September 25, 2017

Dear Prof. Jose Obeso,

Thank you for the opportunity to revise our article, 'Predicting the onset of freezing of gait: A longitudinal study'. Please see attached our responses to the reviewer's comments. We hope our article will now be suitable for publication in Movement Disorders.

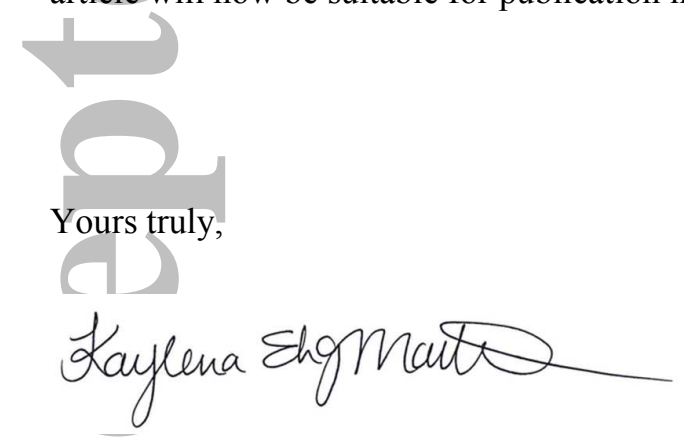

Kaylena Ehgoetz Martens

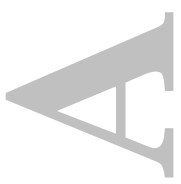


Reviewer: 1

Comments to the Author

The manuscript presents an analysis aimed at creating a predictive profile for FOG. This is an important and difficult issue and the paper is well written and interesting. Below are some suggestions to help clarify some points.

As $80 \%$ of patients will develop PD eventually, it may be possible that a 1-year assessment is not enough to assess prediction in all subjects and that additional factors contribute to these models. This should be mentioned.

This is a fair and excellent point that has now been elaborated on in the discussion (page 14).

Page 14: "Since 80\% of patients will develop PD eventually, it is likely that a 1-year assessment is not enough and additional factors that were not measured here may also contribute to these prediction models. Thus, future research should consider flagging and following 'at-risk' individuals for a longer period, beyond the timeframe captured in this study to determine whether the predictive accuracy improves over time."

Was a video of FOG presented to the patients before answering the FOG Q? Despite FOGQ being the gold standard, are the authors certain that the groups are "clean" based on this selfreport questionnaire?

We acknowledge that a video was not presented to participants, although many the participants had clinically confirmed freezing and have taken part in other freezing of gait studies which behaviorally provoke FOG. Additionally, given that the FOG-Q scores were dissociable between groups and consistent in the non-freezers and continuing freezers (see Figure below), we are confident that our groups reflect those who truly developed freezing. When possible, we also confirmed that the participant continued to report FOG in subsequent visits. Nonetheless, we have added this as a limitation of the study since future work should aim to provide a video and even clinically confirm all participants who report freezing of gait (page 15).

Page 15: "A second limitation that should be noted is that a subjective questionnaire was used to classify freezers, rather than an objective measure of freezing, which may be superior at detecting freezers and minimizing misclassification. In the current study, a video of FOG was not presented to participants prior to answering the $F O G-Q$, although many of the participants had clinically confirmed freezing, and continued to report FOG in subsequent visits. Nonetheless, future work should aim to utilize a video of FOG to minimize classification errors and if possible clinically confirm all participants who report FOG." 


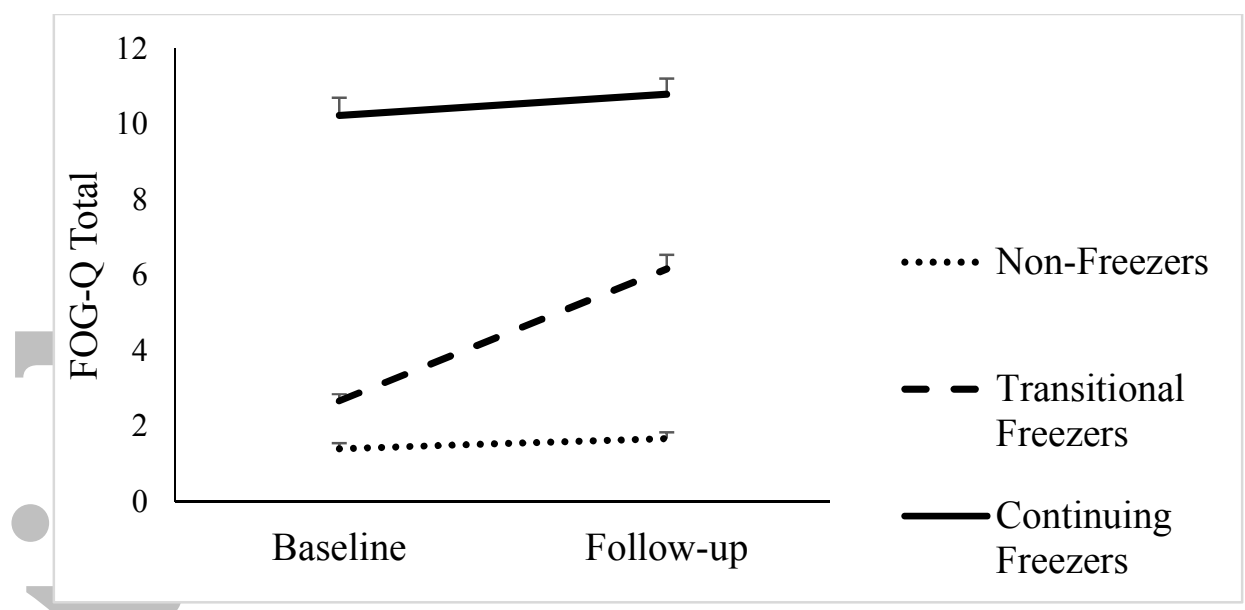

There is no account for severity of FOG (either frequency or duration) but rather the dichotomous answer on Q3 is used for grouping. It would be interesting to understand the association between severity and the cognition and anxiety factors (and add to the discussion on page 14 lines 23-30)

Thank you for this suggestion, we have added your suggested correlational analyses (reported in Table 2, and below) to further describe the association between frequency and severity of FOG with cognition and anxiety. We demonstrate that the severity of FOG measured by the total score of the FOG-Q (including the item 3), was related to worsened cognition regardless of neuropsychological assessment. Furthermore, greater affective symptom severity (worsened depression and anxiety) was also associated with worse FOG severity. We have also added further comment on these relationships in the discussion as per your suggestion (page 13):

Page 7: "To further unpack the relationship between freezing of gait (frequency and severity) and cognitive and affective factors, correlational analyses were also carried out on baseline data (see Table 2)."

Page 8: "Table 2 illustrates the relationship between freezing severity and cognitive and affective symptoms across all participants."

Page 13: "Furthermore, the severity of FOG measured by the total score on the FOG-Q (including item 3) was associated with worsened cognition (regardless of neuropsychological assessment), greater affective symptom severity and greater RBD scores. Taken together, these findings might suggest that cognitive dysfunction and sleep disturbances either become gradually more impaired as FOG onset approaches as a function of disease progression, or that FOG onset, and impaired cognition and sleep occur within a similar timeframe because of shared neurobiological underpinnings such as cholinergic denervation within the pedunculopontine nucleus for example." 
Table 2. Relationships between freezing severity and cognitive, affective and sleep symptoms.

\begin{tabular}{|c|c|}
\hline & $\begin{array}{l}\text { FOGQ-Total } \\
\text { (severity) }\end{array}$ \\
\hline MMSE & $-0.409 * *$ \\
\hline TMT-A & $-0.288 * *$ \\
\hline TMT-B & $-0.218^{*}$ \\
\hline Digit Span Forwards & $-0.232 * *$ \\
\hline Digit Span Backwards & $-0.245 * *$ \\
\hline LM-I & $-0.305^{*} *$ \\
\hline LM-II & $-0.272 * *$ \\
\hline HADS-A & $0.206^{* *}$ \\
\hline HADS-D & $0.499 * *$ \\
\hline RBDSQ4 & $0.185 * *$ \\
\hline
\end{tabular}

$* \mathrm{p}<0.05$

$* * \mathrm{p}<0.01$

The authors did mention the lack of consistent DDE but the possible improvement in symptoms that is seen in table 1 (and their influence on this model) should also be discussed.

Thank you for this interesting comment. Given that the model did not include the continuing freezers who demonstrated a reduction in DDE over the year, it is not entirely clear how $D D E$ may have influenced the model. Although DDE was positively related to FOG severity at baseline, the change in DDE over the one year period was not related to FOG severity. Our suspicion is that since DDE is typically associated with Disease duration and symptom severity, it would contribute in a similar way to these other variables that were included in the model (page 15).

Page 15: "A limitation of this study was the lack of DDE data for numerous participants, which led us to exclude DDE from the logistic regression. Since DDE is typically associated with disease duration and symptom severity, it might be expected to contribute in a similar way to these other variables that were included in the model. Alternatively, given that dopaminergic dysfunction may impact the degree to which network loops crossover, dopamine agonists may play a crucial role in the development of FOG and may be a predictive factor worth exploring in future research."

The analysis suggests a linear relationship in which the measures change between first and second assessment points without interaction between them or their time of appearance. It is likely that progression early in the disease is slower than later during the disease in which reserve capacity is lower. It is likely that the high sensitivity of the model in predicting transition within 1 year is also a factor of the time at which this is measured in terms of disease severity and disease duration. It would be useful to see how this model responds when adjusted for these factors and interesting to speculate on this.

Thank you for this comment. We would like to clarify that this analysis was not a linear regression but instead a logistic regression which measured the relationship between the categorical dependent variable and many independent variables by estimating probabilities using a logistic function. Notably, age, disease duration, disease severity, and tremor dominant ratio were entered into the model to try and account for factors that might reflect 
varying levels of disease progression. Thus, it is unclear which factors the model may have been unadjusted for. A range of cognitive tests were also entered into the model which presumably captures aspects of reserve capacity. We hope this clarifies your inquiry.
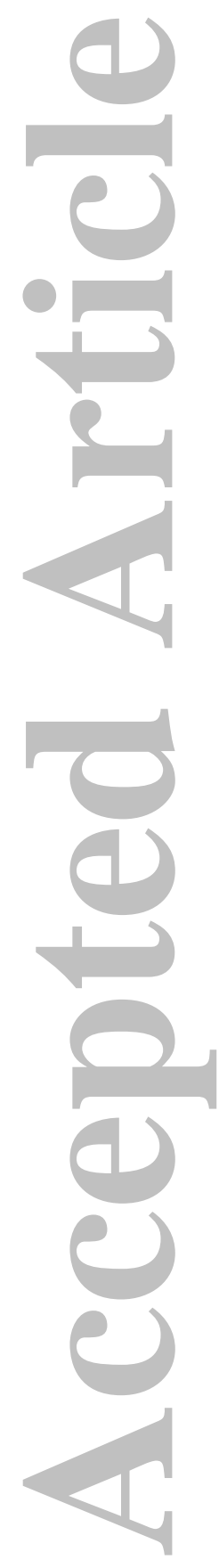

John Wiley \& Sons

This article is protected by copyright. All rights reserved. 


\section{University Library}

\section{- M M N E R VA A gateway to Melbourne's research publications}

Minerva Access is the Institutional Repository of The University of Melbourne

\section{Author/s:}

Martens, KAE;Lukasik, EL;Georgiades, MJ;Gilat, M;Hall, JM;Walton, CC;Lewis, SJG

Title:

Predicting the Onset of Freezing of Gait: A Longitudinal Study

Date:

2018-01-01

Citation:

Martens, K. A. E., Lukasik, E. L., Georgiades, M. J., Gilat, M., Hall, J. M., Walton, C. C. \& Lewis, S. J. G. (2018). Predicting the Onset of Freezing of Gait: A Longitudinal Study. MOVEMENT DISORDERS, 33 (1), pp.128-135. https://doi.org/10.1002/mds.27208.

Persistent Link:

http://hdl.handle.net/11343/261103 